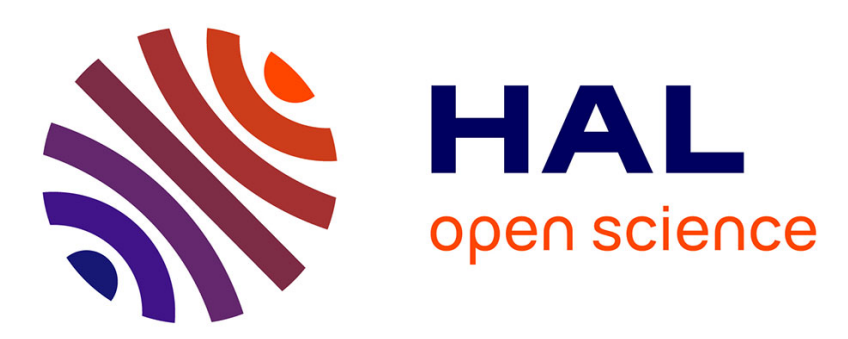

\title{
A Personal Perspective on the Use of Modelling Simulation for Polymer Melt Processing
}

\author{
Jean-François Agassant, Malcolm R. Mackley
}

\section{To cite this version:}

Jean-François Agassant, Malcolm R. Mackley. A Personal Perspective on the Use of Modelling Simulation for Polymer Melt Processing. International Polymer Processing, 2015, 30 (1), pp.121-140. 10.3139/217.3020 . hal-01133118

\section{HAL Id: hal-01133118}

https://hal-mines-paristech.archives-ouvertes.fr/hal-01133118

Submitted on 2 Apr 2015

HAL is a multi-disciplinary open access archive for the deposit and dissemination of scientific research documents, whether they are published or not. The documents may come from teaching and research institutions in France or abroad, or from public or private research centers.
L'archive ouverte pluridisciplinaire HAL, est destinée au dépôt et à la diffusion de documents scientifiques de niveau recherche, publiés ou non, émanant des établissements d'enseignement et de recherche français ou étrangers, des laboratoires publics ou privés. 


\title{
A personal perspective on the use of modelling simulation for polymer melt processing
}

\author{
by \\ J.F.Agassant \\ Mines-ParisTech, CEMEF, UMR CNRS 7635, 06560 Valbonne, France \\ M.R.Mackley \\ Department of Chemical Engineering and Biotechnology, University of Cambridge, \\ CB2 3RA, UK
}

\begin{abstract}
Summary:
This paper gives a personal view on the state of art in relation to the modelling of polymer melt processing. The paper briefly reviews both industrial, laboratory and modelling developments over the last forty years and highlights the key aspects now required for realistic modelling of polymer melt extrusion processing. The paper summarizes elements relating to the numerical simulation of specific and general polymer processes and also provides topical examples of the application of numerical modelling to certain commercial processes. The paper concludes with identifying areas of polymer processing that still remain a challenge in relation to accurate prediction.
\end{abstract}

Key words: Polymer processing, Rheology, Modeling

\section{Introduction}

Numerical modeling of polymer processing has now become an important tool in relation to the cost effective design and operation of commercial polymer processes. In the past, the empirical development of new polymer grades has been motivated largely by searching for new or improved properties and it was assumed that the forming processes used to produce end products could be adapted through laboratory based adjustments made by simple trial and error. This worked effectively for a number of early cases; however sometimes it was discovered that new polymers with predicted "exceptional" properties were very difficult to process, either because the required pressure or torque could not be obtained with existing machines, or because the process exhibited either flow or drawing instabilities at production rates inconsistent with their economic viability. It will be recalled for example the development of metallocene polyethylenes which initially exhibited polymer melt extrusion defects at shear rates as low as $1 \mathrm{~s}^{-1}$ (see for example Agassant et al 2006).

More recently, polymer producers have integrated the forming process into their development of new materials by using at an early stage of the development miniprocessing machines (extruders or injection molding) that could discern potential processing problems using just a few hundred grams of polymer. Sometimes, the extrapolation to 
industrial size machines has proved uncertain, particularly because "scaling" does not obey the same scaling rules for mechanical and thermal behavior.

Numerical modeling, used initially mainly for the last twenty years in the field of injection mold design, has now become an important design aid tool in different sectors of the commercial plastics industry, but it only makes sense to do this if the modeling is based on sound physical principles and the applied numerical techniques can capture the relevant process physics.

This article briefly reviews the background to polymer processing development in the last forty years and the way rheological understanding and laboratory polymer processing experiments have aided further understanding. In parallel with these developments there has been considerable advances in modelling and numerical techniques that now enable complex polymer process situations to be modelled using complex fluid models. The current situation is reviewed and examples given, together with the identification of areas that still remain a challenge for modelling

\section{Background to polymer processing, rheology and modelling}

\subsection{The development of Industrial processes.}

Most of the industrial processing methods existing today (single screw or twin screw extrusion, injection, blow molding, film blowing, calendering ... ) were developed just before or after the Second World War and at the same time as the development itself of major commodity polymers. Some of the processing techniques were themselves inspired from related industries such as food processing or the rubber industry. Since the 1950s, continuous development has been observed and this has been related to some spectacular progress and some examples are given below

In single-screw extrusion, incremental improvements have led to a doubling of extrusion rates every 5 to 10 years. The Maillefer patent (1959) introduced the splitting of the solid polymer granules or powder from the molten zone during the plastication process, thereby increasing the "plasticization rate" and the process stability. The progressive introduction of mixing elements has improved both distributive and dispersive mixing (Rauwendaal, 2001). Grooved sleeves at the feed zone of the machine has improved the conveying of solid granules (Potente and Schöppner, 1995) and two-stage extruders have allowed efficient degassing at high throughput (Vergnes et al., 1986).

In twin-screw extrusion, the most significant progress concerns co-rotating extruders where an optimized combination of right and left handed conveying elements and kneading elements have made these extruders very effective mixing tools as well as continuous chemical reactors (Agassant et al.,2014, Lafleur and Vergnes, 2014) .

Extrusion lines have also showed significant progress. In the case of film blowing, sophisticated double flux air rings help govern the shape of the bubble regardless of the rheology of polymer. Coupled with internal cooling devices, they allow better control of the final film properties (isotropic elastic modulus, transparency, impact resistance) (Gamache, 2010).

In injection molding there have been many developments including the use of hot runners to improve the packing stage and this has led to a better control of the weight and dimensions of the produced parts. Peripheral devices have enabled the automated extraction of molded parts and continuous dimensional control.

Other major developments include High speed twin-screw extruders (> $1500 \mathrm{rpm}$ ) able to deliver very high output rates (up to 100 tons / hour), coextrusion units that allow feeding a single die with a large number of polymers to make multilayer films or hollow bodies, the 
development of electric injection molding machines that enable significant energy savings, a more stable process and also the realization of injection molding "clean rooms" for electronic or medical applications, gas or water assisted injection (Dreyer, 2012) which help prevent shrinkage, while reducing the cycle time and the weight of the injected parts without altering the final mechanical properties, microinjection allowing production of parts whose weight may be a few milligrams (for watches, precision engineering or the medical field) where this requires special mold machining processes, very small plasticizing units, very fast injection speeds, suitable part gripping and control devices. Finally, the development of the injection stretch blow-molding process has now been used for ten years producing almost all of the world carbonated plastic beverages bottles (especially PET) (Plantamura, 2012).

\subsection{The Development of new polymer materials}

Many commodity polymers were developed before or just after the second world war and the steady development in polymer processing equipment and the need for improved properties and quality control for the produced plastic parts has resulted in the ever greater precision and complexity of the thermoplastic polymers used. This in turn has required highly specified polymer compositions and architecture in order that quality products can be produced in a highly reproducible way and at an economically viable rate. The development of technical polymers, of polymer blends, reinforced polymers, and more recently of biopolymers that are required to be processed in existing machines, has initiated processing issues which in turn has motivated a greater need for the understanding of the polymer rheology.

\subsection{Modeling polymer processing}

The modeling reviewed in this paper focuses on the manufacturing processes of thermoplastic polymers, which may or may not be reinforced with additives or discontinuous fibers. With these materials continuum mechanics can be applied. This type of analysis cannot however be necessarily applied to thermoset polymers and elastomers, even if some of the approaches developed are applicable.

Shaping thermoplastic polymers is a thermo-mechanical process which requires generally three successive steps:

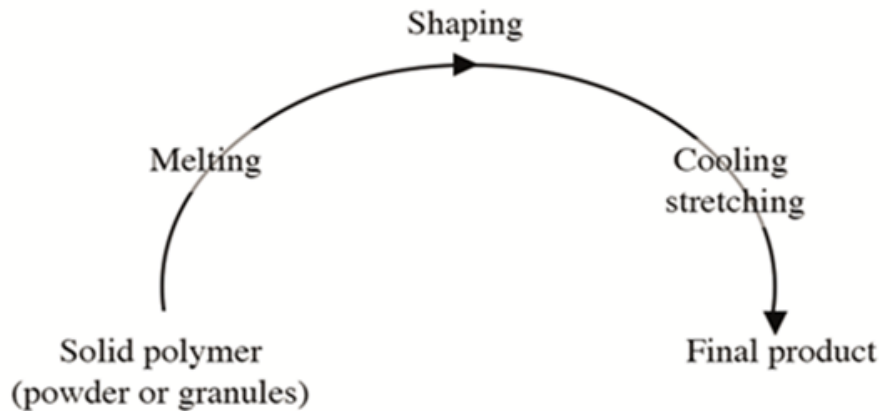

Figure 1: General procedure for polymer processing

- Melting, that is to say the passage of the solid state, powder or granules, to a molten state in order to give a sufficiently fluid and homogeneous melt.

- $\quad$ Flow of the molten polymer under pressure through a die or into a mold, shaping cooling, possibly coupled with drawing operations, biaxial stretching, blowing. 
- Solidification into the final component shape and form.

The properties of the produced part will depend, of course, on the chosen polymer, but also on the "thermo-mechanical path" that was followed to shape the object.

In the light of figure 1, it can be imagined that polymer processing is a simple problem of fluid mechanics coupled to heat transfer. In reality it is more complicated because rheology and heat transfer of thermoplastic polymers produce both experimental and modeling challenges. As the rheological understanding of molten polymers has improved, more sophisticated rheological models have been developed from simple power law modelling to multimode differential or integral viscoelastic models. At the same time, applied mathematicians were developing tools to numerically simulate complex flow geometries, first with purely Newtonian behavior and then with more sophisticated viscous, viscoelastic and temperature dependent constitutive equations. One of the early examples was a 2D entry flow (Black et al 1975) and this has been followed by intensive development which has resulted in commercial software now being available that simulate complex polymer processing geometries with a complex rheology behaviour. For current commercial software, see for example;

Moldflow,

http://www.autodesk.co.uk/products/autodesk-simulation

family/features/simulationmoldflow/all/gallery-view.

Polyflow,

http://www.ansys.com/Products/Simulation+Technology/Fluid+Dynamics/Specialized+Produ cts/ANSYS+Polyflow

Rem3D,

http://www.transvalor.com/en/cmspages/rem3d.7.html.

\section{Fundamentals relevant to polymer processing modelling.}

Even with the availability of current "black box" sophisticated commercial polymer processing software, an appreciation of the key physical parameters relevant to polymer processing is both useful and in some cases necessary. The following section gives an outline of areas which are important in relation to being confident that a numerical simulation will give a realistic and accurate prediction.

A key aspect in successfully modelling polymer processing is to have a realistic model of the rheology of the polymer. Polymer melts generally have high viscosities above say 100 Pas, however they can have dramatic shear thinning characteristics and they can be strongly viscoelastic. The rheology will also be temperature dependent and crucially will also change when the polymer passes from a solid pellet or powder to a melt in the early stages of processing and will also change when subsequent solidification occurs which may or may not involve crystallization. All this, together with the potential for shear heating during processing, compressibility effects and complex heat transfer and kinematic boundary conditions results in a problem of complexity where in a number of cases a "black box" approach to problem solving at best can be misleading and at worst, simply wrong. Several reference books have been devoted to an accurate description of the physics of polymer processes (see for example McKelvey, 1962; Pearson, 1966; Tadmor and Klein, 1970; Agassant et.al, 1991; Dealy and Wissbrun, 1999; Tadmor and Gogos, 2006; Agassant et al., 2014). 


\subsection{The high viscosity of polymer melts}

At processing temperatures, molten polymers generally have a viscosity $(\eta)$ as high as $10^{3} \mathrm{Pas}$, which is a million times larger than water's viscosity and this property has a number of significant consequences:

- Inertia free flow. The Reynolds number $\left(\operatorname{Re}=\frac{\rho U h}{\eta}\right.$ where $\rho$ is the density, $U$ an average velocity and $h$ a characteristic dimension of the flow, for example the gap in the case of a die flow channel) ranks the fluid inertia terms with respect to viscosity terms in the Newtonian Navier-Stokes equations. Because of the polymer high viscosity, the Reynolds number for most polymer flow is low and below unity. As a consequence a normal molten polymer flow will never be turbulent, and often the inertial terms of the force balance equations can be neglected. However on occasions the Reynolds number may be of the order of unity or greater and therefore inertia sometimes needs be accounted for in the force balance equations for high acceleration flows such as pin-point gates for injection molding or for high-speed textile fiber spinning.

- Gravity body forces. The Stokes number $\left(S t=\frac{\rho g L h}{\eta U}\right)$ where $g$ is the gravitational acceleration and $L$ is the vertical dimension of the flow) is negligible in most confined flows, however it may become important in free surface processes as in film blowing, fiber spinning and extrusion blow molding for large hollow bodies.

- Shear heating. Heating of the polymer by viscous flow dissipation can under certain circumstances be very significant and this can be used with benefit for example in plasticization units: In many common extrusion operating conditions, energy introduced into the polymer by heat conduction and by viscous dissipation are of the same order of magnitude and therefore it is essential when modelling these situations to solve both the thermal and force balance coupled equations.

- High pressures. For flows in extrusion dies and injection molds the flow pressures are typically $100 \mathrm{MPa}$ or more in injection molding and 5 to $50 \mathrm{MPa}$ in extrusion heads. This pressure is achieved by two main methods. In injection molding, the screw stops its rotation in the plasticization barrel unit after the melting phase and then acts as a piston during the filling and post-filling phases of the mold cavity. In continuous extrusion, the screw-barrel system acts as a pump: the pressure generated in the extruder head results from the balance between the flow in the channel of the screw on the one hand and in the downstream die on the other hand. These high pressures can result in compressibility effects becoming important and also pressure dependent factors need to be taken into account.

\subsection{The nonlinear behavior of molten polymers:}

In the 1960s a single measure of melt flow index was used to characterise a certain polymer (see for example Gleissle 1998) and a simple Newtonian viscosity was used for the first polymer process models. Subsequently the shear thinning characteristics of polymers were taken into account. Since the early 1980s a greater appreciation of viscoelasticity developed and viscoelastic relaxation spectra (see for example Mackley et al., 1994) started to be used and linked with the polymer molecular weight distribution (see for example Ruymbeke et al., 2002). When modelling, the two distinct forms of shear thinning and viscoelasticty may need to be considered which are both related to the behavior of polymers during flow: 
a) Pseudoplastic (shear-thinning) behavior: Typically, the viscosity of a molten polymer may decrease by a factor 5 when the shear rate is increased by a factor of 10 . If the polymer's viscosity was constant (Newtonian), the doubling of the processing machine velocity would result in a doubling of the pressure required to flow in a die or in a mold. The high shear thinning sensitivity of the viscosity to the strain rate and the temperature dependence of viscosity permits a wide variation of operating parameters while retaining die head or injection pressures of the same order of magnitude. To account for this phenomenon, a "power law" (also called Oswald de Waele law) is often used:

$$
\boldsymbol{\sigma}=-p \mathbf{I}+\mathbf{s} \quad \mathbf{s}=2 K \dot{\bar{\gamma}}^{m-1} \dot{\boldsymbol{\varepsilon}}
$$

Where $\boldsymbol{\sigma}$ is the stress tensor, $\mathbf{s}$ the deviatoric stress tensor, $\dot{\boldsymbol{\varepsilon}}$ the rate of strain tensor, $\mathbf{I}$ the identity tensor, $\dot{\bar{\gamma}}=\sqrt{2 \sum_{i j} \dot{\varepsilon}_{i j}^{2}}, K$ is the consistency of the polymer, $m$ the power-law index.

This equation makes analytical resolution possible in several simple flow situations, but presents the drawback of not accounting for the existence of a Newtonian plateau at low rate of strain. For this reason, it is sometimes preferable to use a Cross (1965) or a CarreauYasuda law (Yasuda et al., 1981) which has the form:

$$
\mathbf{s}=2\left[\eta_{0}\left(1+(\lambda \dot{\bar{\gamma}})^{a}\right]^{\frac{m-1}{a}} \dot{\boldsymbol{\varepsilon}}\right.
$$

where $\eta_{0}$ is the viscosity at the Newtonian plateau, $\lambda$ an average relaxation time and $a$ a parameter for adjusting the transition between the Newtonian plateau and the shear rate range where the viscosity of the polymer is sensitive to the strain rate .

These parameters are usually readily measurable using a cone-plate (or parallel plate) rheometer in a continuous or dynamic modes, or by using a capillary rheometer.

b) Viscoelastic behavior: Viscoelasticity can play a more subtle and sometimes more important role than viscous shear thinning. Viscoelasticity can stabilize stretching or biaxial stretching of polymer melts and this makes spinning of polymers at high strain rate, blow molding and thermoforming possible. In contrast, viscoelastic effects can cause difficulties in confined shear flows due to the occurrence of viscoelastic flow instabilities, which can result in distorted extrusions, surface defects called "shark skin", melt-fracture or spurt in extrusion (Kalika and Denn, 1987; McKinley et al., 1996; Agassant et al., 2006) and in interface instabilities in coextrusion (Wilson and Khomami, 1993; Valette et al., 2004). Viscoelasticity is also responsible for a die swelling phenomena at an extrusion die exit which can greatly complicate tool design and extrusion processing.

An impressive range of viscoelastic behavior constitutive equations are now available and some are based on phenomenological approaches (combinations of springs and dashpots). The simplest form is the Upper Convected Maxwell model which is given by:

$$
\boldsymbol{\sigma}=\boldsymbol{\sigma}^{\prime}-p^{\prime} \mathbf{I} \quad \boldsymbol{\sigma}^{\prime}+\lambda \frac{\delta \boldsymbol{\sigma}^{\prime}}{\delta t}=2 \eta \dot{\boldsymbol{\varepsilon}} \quad \frac{\delta \boldsymbol{\sigma}^{\prime}}{\delta t}=\frac{d \boldsymbol{\sigma}^{\prime}}{d t}-\nabla \mathbf{u} \cdot \boldsymbol{\sigma}^{\prime}-\boldsymbol{\sigma}^{\prime} \cdot(\nabla \mathbf{u})^{\mathrm{t}}
$$

where $\boldsymbol{\sigma}^{\prime}$ is the extra- stress tensor, $p^{\prime}$ an arbitrary pressure and $\nabla \mathbf{u}$ the velocity gradient tensor.

The Upper Convected Maxwell model has been generalized to account for the sensitivity of the viscosity and the relaxation time to the rate of stain (White- Metzner, 1963) or to limit the growth of the extensional viscosity (Phan -Thien Tanner, 1977). Moreover, this law can be generalized in a multimode form where: $\boldsymbol{\sigma}=-p^{\prime} \mathbf{I}+\sum_{i} \boldsymbol{\sigma}_{\mathbf{i}}^{\prime}$ with each $\boldsymbol{\sigma}_{\mathbf{i}}^{\prime}$ obeying to the 
Maxwell law (with a set of $\left(\eta_{i}, \lambda_{i}\right)$ corresponding to the respective spectrum of relaxation times).

Integral formulation is the most intuitive way to build a viscoelastic constitutive equation. The Lodge model (Lodge, 1964) corresponds to the upper-convective Maxwell model. Enriched integral models have been proposed by Wagner (1976) and Papanastasiou et al. (1987). These integral constitutive equations are very interesting in simple flow geometries, but difficult to manage in the complex flow geometries as those encountered in most polymer processes.

It is now also possible to build molecular constitutive equations that take into account the local topology of the macromolecules. One can mention the Pom-Pom model (McLeish and Larson, 1998), the Rolie-Poly model (Likhtman and Graham 2003) and the MarrucciIanniruberto model (2003) which written for a single mode has the following form:

$$
\begin{gathered}
\boldsymbol{\sigma}^{\prime}=3 G f\left(\mathbf{C}-\frac{1}{3} \mathbf{I}\right) \quad \dot{\mathbf{C}}=\nabla \mathbf{u} \mathbf{C}+\mathbf{C} \nabla^{t} \mathbf{u}-\frac{f}{\lambda^{*}}\left(\mathbf{C}-\frac{1}{3} I_{C} \mathbf{I}\right)-\frac{1}{3 \lambda_{R}}\left(f I_{C}-1\right) \mathbf{I} \\
\frac{1}{\lambda^{*}}=\frac{1}{\lambda}+\left(\frac{1}{\lambda_{R}}-\frac{1}{\lambda}\right) \frac{\beta\left(f I_{C}-1\right)}{1+\beta\left(f I_{C}-1\right)} \quad f=\frac{b-1}{b-I_{C}}
\end{gathered}
$$

where $G$ is the elastic modulus, $\mathbf{C}$ the orientation tensor, $I_{c}$ the trace of $\mathbf{C}, b$ a parameter that reflects the maximum deformation of the macromolecule, $\lambda_{R}$ the relaxation time of the macromolecule orientation and $\beta$ a parameter that takes into account the topological constraints imposed by the surrounding macromolecules (CCR, Convective Constraint Release). Some parameters of these viscoelastic constitutive equations can be deduced from dynamic rheology measurements (complex modulus) but other non linear parameters are difficult to measure with common rheological tools (cone and plate, capillary or even elongation rheometers).

c) The choice of a relevant constitutive equation: The most sophisticated constitutive equation is not necessarily the most relevant or useful for modeling engineering processes. The choice depends on the process to be solved, on the type of flow, on the available computer facilities and, of course, on the available rheological measurements.

If the objective of the calculation is to know the stress distribution, the orientation of macromolecules or of short glass reinforcing fibers, it is necessary to introduce a viscoelastic behavior law. If, however, the aim is only to establish pressure flow-rate relationships (and thus the velocity field) the choice will depend largely on the nature of the flow:

In a confined simple shear flow or shear dominant flow (meaning that the hydrodynamic or Hele-Shaw approximations, which will be presented in the next section, can be applied) it is necessary to take into account accurately the shear rate and temperature dependence of the viscosity. In that kind of geometry, viscoelasticity modifies only marginally the velocity field and the normal stress at the wall (which is often incorrectly called pressure).

In an extensional flow with a free surface, it is usually essential to use a viscoelastic law because only this type of behavior is able to account for the often experimentally observed increase in extensional viscosity with the elongation rate.

In mixed flows where there is a competition between shear and elongation, dimensionless numbers allow weighting the magnitude of viscoelastic phenomena: if the Deborah number ( $D e=\frac{\lambda U}{L}$ ), which balances a characteristic time of the polymer $\lambda$ by a characteristic time of the process $(L / U)$, is small compared to unity, the flow can be consider 
as established, that is to say that the transients can be neglected. The difficulty is to define a relevant characteristic time of the polymer in the relaxation times distribution. If the Weissenberg number ( $W e=\frac{N_{1}}{2 \tau}$ ), which weighs the first normal stress difference $N_{l}$ by the shear stress $\tau$ is small compared to unity, elastic stresses can be neglected compared to those of viscous origin. If the Weissenberg and Deborah numbers are large, it is necessary to use a viscoelastic calculation, but this is not a trivial task because of flow singularities (the re-entrant corner in a die, the die exit) and of the convection terms in the viscoelastic constitutive equations that will "carry" and amplify singularity constraints (Keunings, 1989).

\subsection{Temperature effects}

The low thermal conductivity of polymers as well as the temperature dependence of the viscosity introduce specific problems which may need to be addressed when solving polymer processing problems. The thermal conductivity of most polymers is of the order 0.2 $\mathrm{W} . \mathrm{m}^{-1} \cdot{ }^{\circ} \mathrm{C}^{-1}$, a thousand times lower than copper. Under these conditions, it takes about 17 minutes for conductive surface heating to reach a depth of $1 \mathrm{~cm}$ within a polymer, $10 \mathrm{~s}$ for a depth of $1 \mathrm{~mm}$ and $0.1 \mathrm{~s}$ for a depth of $0.1 \mathrm{~mm}$. This illustrates for example that polymer melting by pure conduction requires a very long time and this would lead to inadmissible production rates. That is why most commercial melting processes require a significant input of internal mechanical viscous energy dissipation, which is often much higher than the simple thermal conduction energy input. Furthermore, heating by viscous dissipation is localized where both rate of strain and stress are important and the low thermal conductivity of polymer will consequently promote the existence of high thermal gradients. Given the risk of polymer degradation due to these localized overheating phenomena, this limits the amount of energy that can be provided by viscous dissipation and the flow rates that can be obtained.

On the other hand, when a molten polymer emerges from a die, the high viscosity together with low thermal conductivity allows the surface of a polymer extrudate to remain in the molten state for considerable time and hence distance, before passing through a calibrator or being stretched to produce very thin fibers or films. This property has led to the development of many processes: fiber spinning, bottles (and other hollow polymer parts) blow-molding or stretch blow-molding, film blowing, cast film.

Dimensionless numbers allow assessing quickly the magnitude of the phenomena and therefore to decide a priori if a complex resolution coupling mechanical and thermal problems is necessary or not.

- The Cameron number (Cameron, 1966) $C a=\frac{a L}{U h^{2}}$ where $a$ is the thermal diffusivity, balances the convection term in the flow direction and the thermal conduction in the transverse direction (towards the die or mold walls). If this number is less than $10^{-2}$, the flow can be considered as adiabatic and the mean polymer temperature increase is proportional to the pressure drop along the flow ( $\Delta T=\frac{\Delta p}{\rho c}, c$ is the specific heat capacity). If the Cameron number is greater than 1, the thermal equilibrium regime may be assumed to have been established, that is to say the temperature profile will not change any more over the flow length. The temperature difference between the wall and the flow axis will be in the range of $\Delta T=\frac{\eta U^{2}}{k}, k$ is the thermal conductivity of the polymer. Between these two values of the Cameron number, the evaluation of the temperature variation will be more difficult. 
- The Brinkman number $B r=\frac{\eta U^{2}}{k\left(T-T_{p}\right)}$ (Brinkmann, 1951) weights the viscous dissipation to the conduction towards the walls whose temperature is $T_{p}$. If this number is greater than 1, the viscous dissipation will govern the polymer temperature increase and an accurate thermal regulation of the process wall is not required. If, instead, this number is less than 1 , it is the temperature of the metal boundary that will control the temperature of the polymer and this justifies an effective thermal regulation.

- $\quad$ The Nahme number $N a=\frac{k E}{\eta R U^{2}}$ ( $E$ is the activation energy of the viscosity and $R$ the gas constant) weights the sensitivity of the viscosity with respect to the temperature and the heat generated by viscous dissipation. If this number is less than 1 , the mechanical and thermal calculations can be decoupled.

The temperature dependence of the viscosity for molten polymers follows an Arrhenius equation for semi-crystalline polymers and for amorphous polymer $100^{\circ} \mathrm{C}$ above the glass transition temperature $T_{g}$. This allows expressing the viscosity at temperature $T$ as a function of viscosity at a reference temperature $T_{0}$ :

$$
\eta(T)=a_{T} \eta\left(T_{0}\right) \text { with } \log _{T}=\frac{E}{R}\left(\frac{1}{T}-\frac{1}{T_{0}}\right)
$$

For amorphous polymers, between $T_{g}$ and $T_{g}+100^{\circ} \mathrm{C}$, a WLF equation is used (Williams, Landel, Ferry, 1955):

$$
\log a_{T}=-\frac{C_{1}^{g}\left(T-T_{g}\right)}{T-T_{g}+C_{2}^{g}}
$$

The activation energy $E$ as well as the constants $C_{1}^{g}$ and $C_{2}^{g}$ may vary significantly from one polymer to another: for a polystyrene the viscosity may decrease by a factor 2 by increasing the temperature by $20^{\circ} \mathrm{C}$, as the viscosity decrease is only $20 \%$ for a HDPE. The viscosity around $T_{g}$ and in the crystallization temperature range remains an open scientific problem which justifies using the so-called "no flow temperature" in many injection molding softwares.

Shear heating in particular, wall friction and latent heat associated with phase change can also influence both real processing and the matching simulation and so it is generally necessary to solve both flow and thermal equations as coupled equations.

\subsection{Base equations, boundary conditions and model simplification}

Polymer forming is generally carried out in complex tool geometries and in most cases, the flow is three-dimensional. At each point of the flow geometry, it is necessary to know the velocity field $\mathbf{u}(u, v, w)$ (3 components), the stress tensor $\boldsymbol{\sigma}$ (6 components) and the temperature $T$. For compressible flows one may also need to know the density $\rho$, for reactive processing the evolution of the different chemical species, for reinforced polymers the orientation of short fibers or the dispersion of charges. In what follows the flow of an homogeneous and non-reactive polymer is developed.

a) Base equations that can be written are:

$$
\text { - A mass balance equation: } \quad \frac{\partial \rho}{\partial t}+\nabla \cdot(\rho \mathbf{u})=0
$$

Compressibility generally may be neglected in most polymer processing situations. It will however be seen in section 4.1 that it needs to be accounted for in certain Multipass 
Rheometer experiments in order to capture the pressure development and the pressure relaxation. Compressibility is also of importance in injection molding, especially to account for the packing stage (see section 5.5).

When the flow is incompressible the mass balance equation (7) becomes:

$$
\nabla . \mathbf{u}=0
$$

- $\quad$ Three force balance equations: $\quad \nabla \cdot \boldsymbol{\sigma}+\mathbf{F}-\rho \boldsymbol{\gamma}=0$

As explained earlier it is often possible to neglect mass forces $\mathbf{F}$ and inertia forces $\rho \boldsymbol{\gamma}$ and the previous equation becomes:

$$
\nabla \cdot \boldsymbol{\sigma}=0
$$

- Constitutive equations for the rheology can be generally written as: $f\left(\boldsymbol{\sigma}^{\prime}, \dot{\boldsymbol{\varepsilon}}\right)=0$

- $\quad$ A thermal balance equation. In the absence of phase change and for an incompressible material is written as:

$$
\rho c \frac{\partial T}{\partial t}+\rho c(\mathbf{u} \cdot \nabla T)=\nabla \cdot(k \nabla T)+\dot{W}
$$

\section{b) Boundary conditions}

In confined flows (extrusion dies, injection molds), it is generally assumed that the polymer adheres to the metal tool wall, however even for some standard commercial polymers partial slip can be present (see for example Lee and Mackley 2000) . Slip may also occur when processing reinforced polymers, rubbers or PVC compounds and in particular in the melting and solidification stages of polymer processing slip can be important and in some cases dominant. The problem is then to define a realistic sliding law. This gives rise, even today, to scientific debate. It is generally assumed that the slip velocity $V_{g}$ depends only on the shear stress at the wall $\tau_{p}$, i.e. for example: $V_{g}=\alpha\left(\tau_{p}\right)^{n}$ (Mooney, 1931) where $\alpha$ and $n$ are two parameters that can be determined by experimental measurements. Slip can also occur at high throughput; it is then usually associated with the existence of extrusion defects.

In free surface flows (fiber spinning, blown film, for example), a velocity tangent at the free surface and a zero normal stress to this free surface are imposed, namely: $\mathbf{u} . \mathbf{n}=0$ and $\boldsymbol{\sigma} \cdot \mathbf{n}=\mathbf{0}$ if the surface tension is neglected. $\mathbf{n}$ is the vector normal to the surface.

In unsteady free surface flows (mold filling, but also blow molding), the stress component normal at the surface is again zero, but now the free surface propagates along the normal to this free surface which writes: $\mathbf{u} \wedge \mathbf{n}=\mathbf{0}$.

Thermal boundary conditions can also present difficulties as the geometry of polymer processing equipment can be complex and wherever there is a free surface involved appropriate heat transfer coefficients must be chosen. In high speed fibre spinning for example, the external heat transfer coefficient from molten polymer to air can have a profound effect on fibre cooling rates and final product dimensions.

c) Model simplification. Solving the above full equations is still a very challenging numerical problem and so in the past it has been traditional to make wherever possible a number of approximations.

- Geometric approximations are the most powerful: They consist for example in unrolling the flow geometry. This is carried out for example to analyze the flow between the screw and the barrel of a single screw extruder (Tadmor and Klein, 1970). They may also consist of decomposing a complex flow geometry into several more simple flow geometries where local mass balance and pressure equilibrium equations can be written (this will be described for simplifying a film blowing die in section 5.2). 
- Hydrodynamic lubrication or Hele-Shaw Approximations (1899): In many polymer processing geometries, the transverse dimension of the flow (the thickness $h(x, y)$ in figure 2) is small compared to the other dimensions and slightly varies in the flow direction.

In the case of an isothermal Newtonian behavior, it helps to reduce the problem of solving 4 equations (Stokes and mass balance equations) with 4 unknowns (the three components of the velocity and the pressure) in the $3 \mathrm{D}$ geometry of figure 5 to a single pressure dependent equation. Boundary conditions are obvious (extrusion pressure imposed at the inlet and zero pressure at the outlet and a zero pressure gradient at the periphery of the flow). These lubrication approximations consist in fact in neglecting the velocity component perpendicular to the mid-plane of the flow as well as the elongation rates and the shear rates in the midplane (xOy) in front of the shear terms in the thickness (in the planes $(\mathrm{xOz})$ and $(\mathrm{yOz})$ ) .

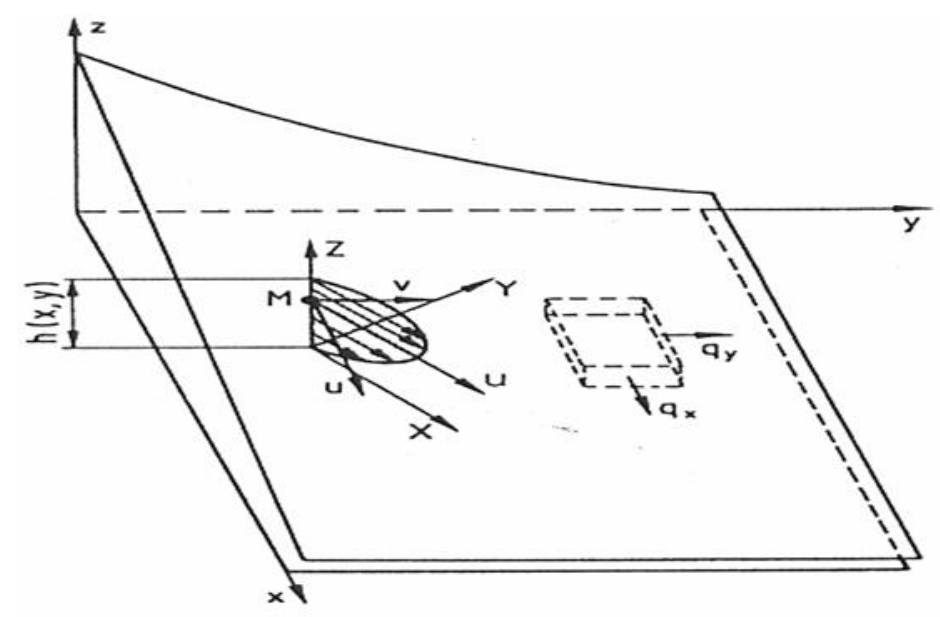

Figure 2: Typical Hele-Shaw flow geometry; the flow is along $\boldsymbol{u}$ in the $(x, y)$ plane

$$
\begin{aligned}
& \frac{d p}{d x}=\eta\left(\frac{\partial^{2} u}{\partial x^{2}}+\frac{\partial^{2} u}{\partial y^{2}}+\frac{\partial^{2} u}{\partial z^{2}}\right) \\
& \frac{d p}{d y}=\eta\left(\frac{\partial^{2} v}{\partial x^{2}}+\frac{\partial^{2} v}{\partial y^{2}}+\frac{\partial^{2} v}{\partial z^{2}}\right) \\
& \frac{d p}{d z}=\eta\left(\frac{\partial^{2} w}{\partial x^{2}}+\frac{\partial^{2} w}{\partial y^{2}}+\frac{\partial^{2} w}{\partial z^{2}}\right) \\
& \frac{\partial u}{\partial x}+\frac{\partial v}{\partial y}+\frac{\partial w}{\partial z}=0
\end{aligned}
$$

$$
h \Delta p+3\left(\frac{\partial p}{\partial x} \frac{\partial h}{\partial x}+\frac{\partial p}{\partial y} \frac{\partial h}{\partial y}\right)=0(13)
$$

This Hele-Shaw equation can be generalized to more general temperature dependent viscous behavior.

- Thin film or fiber approximation: When considering, for example, the drawing of a fluid filament (figure 9), the velocity field can be written, assuming the flow is axisymmetric and the velocity component in the stretching direction $\mathrm{z}$ is uniform in each section: $\mathbf{u}=(u(r, z), 0, w(z))$.

The continuity equation allows the radial velocity component of the flow $u(r, z)$ to be written as a function of $w(z): u(r, z)=-\frac{r}{2} \frac{d w}{d z}$

The thin fiber approximation consists of neglecting the shear terms in relation to the elongation terms. Assuming a Newtonian isothermal fluid behavior and neglecting friction 
forces exerted by the surrounding air leads to the well-known Trouton equation (1906): $\sigma_{z z}=3 \eta \frac{d w}{d z}$

If inertia and gravity terms are neglected as well, the stretching force is constant, which can be written, taking into account the continuity of the flow rate $\mathrm{Q}$ :

$$
\frac{d}{d z}\left(3 \eta \frac{Q}{w(z)} \frac{d w}{d z}\right)=0
$$

These approximations result in a single equation whose only unknown is the velocity field. They may be extended to film or membrane geometries and applied to the fiber spinning process in section 5.1..

- $\quad$ Certain approximations can also be made to the thermal equation (12). For thin layer geometries an average temperature balance equation may be written on a material volume $(h d x d y)$ around point $\mathrm{M}$ of coordinates (x, y) (figure2):

$$
\bar{u}(x, y) h(x, y)\left[\frac{\partial \bar{T}}{\partial x}+\frac{1}{\rho c} \frac{\partial p}{\partial x}\right]+\bar{v}(x, y) h(x, y)\left[\frac{\partial \bar{T}}{\partial y}+\frac{1}{\rho c} \frac{\partial p}{\partial y}\right]=\frac{2 k}{\rho c} N u \frac{T_{p}-\bar{T}}{h(x, y)}
$$

with $\bar{u}$ and $\bar{v}$ being the mean velocity components at point $\mathrm{M}$ and $T_{p}$ the temperature of the tool. The Nüsselt number $N u$ represents a non-dimensional heat transfer coefficient $h_{T}$ : $N u=h_{T} \frac{h}{k}$

Knowing the pressure field and the velocity field thanks to the Hele-Shaw approximation, the solution of this equation will quickly provide the order of magnitude of thermal phenomena. An iteration loop will be required if the temperature variations are too large. The validity of this average temperature approach will depend on the accuracy of the estimation of the heat transfer coefficient (i.e. the Nüsselt number $\mathrm{Nu}$ ) and the importance of the temperature difference between the wall of the tool and the polymer. When this difference is small (as it is generally the case in extrusion dies or between calender rolls), the precision of these approximations may be sufficient. It is however doubtful if this difference is large (in the case of injection molding, for example).

\subsection{Numerical schemes}

In any three-dimensional flow there are ten equations that provides access to the ten unknowns that have to be solved. Several numerical methods are available.

- In "direct" methods, a CAD definition of the die or mold geometry allows meshing the 3D flow volume within this geometry and then solving the set of ten equations in this volume using finite elements, finite volumes or finite differences methods. Meshing is a key point for obtaining an accurate result while controlling the computation time. Figure 3 presents the obtained mesh of a complex cavity mold where capturing the flow in narrow flow regions, as the one around the injection gate, requires a very refined mesh. Extending this refined mesh to the whole geometry would lead to several millions of nodes and very large computation times and facilities. The development of anisotropic meshes (refined in the thickness and coarse in the flow direction) and of local mesh refinement governed by the local flow metric (Coupez, 2011; Coupez and Hachem, 2013) allows reducing significantly computation time and improving accuracy. Finite element methods are the most popular. One difficult point is to choose appropriate finite elements and the related approximations spaces in order to respect the compatibility conditions for velocity, pressure (and stress components when using viscoelastic constitutive equations) (Arnold et al, 1984). Another difficulty is to deal with the 
convective terms, especially for viscoelastic constitutive equations (Brooks and Hughes,1982; et al;, Silva et al.,2012))

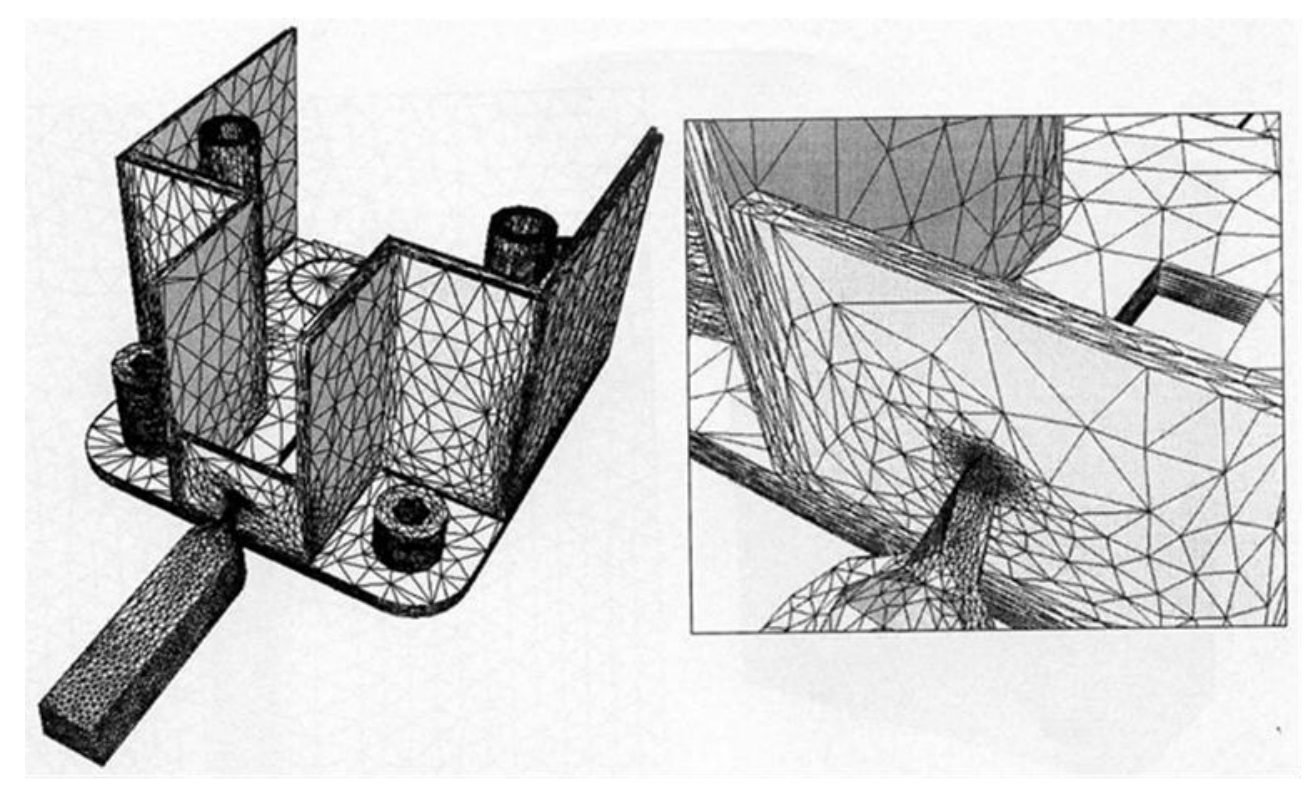

Figure 3: Example of a mold cavity meshing with sharp mesh refinement in the vicinity of the injection gate (Silva et al., 2009)

- In many cases, however, the tooling geometries are such that geometric and kinematic approximations may be used. Moreover, the different thermal dimensionless numbers listed above allow simplifying the temperature balance equation and provide a good order of magnitude of thermal phenomena.

- The choice between direct numerical methods and approximation methods is not obvious: Direct methods are difficult to implement and costly in computation time and memory space, which makes them tedious for parametric studies that require forming tool optimization. Moreover, the accuracy of the result depends on the accuracy of the mesh and, in the case of complex three-dimensional flows, mesh refinement until a stabilized numerical solution is not always possible. Approximation methods are obviously much faster, but the results depend on the validity of the approximations made. Nevertheless, these quick calculations allow easier parametric optimization.

\section{Laboratory experimental flow geometries}

Most industrial polymer processing equipment is complex and not readily amenable to either visual interrogation or systematic variation of external variables and this has made it difficult to establish the validity of otherwise of numerical simulation predictions for many industrial commercial processes. In an attempt to overcome this problem a number of laboratory "prototype" experimental apparatus have been built in order to make a direct comparison with numerical simulation using geometries of sufficient complexity that they capture most aspects of commercial processing (see for example Lee and Mackley, 2001). Both authors of this paper (see for example Agassant et al., 2002) have been very involved in this procedure, as quantitative validation of numerical simulation was seen as an important step to help support the use of simulation on industrial processes. 


\subsection{Multipass rheometer}

The Multipass rheometer (MPR) is an apparatus specifically designed to provide precise conditions for polymer melt processing (see for example review Mackley and Hassell, 2011). The two piston apparatus can be used with an optical attachment and direct comparison between flow birefringence stress patterns and numerical prediction can be made. Figure 4 is an example where the stress pattern of a commercial polyethylene is directly compared with that of a Polyflow numerical simulation using a multimode integral Wagner constitutive equation (Lee and Mackley, 2001). The fit between experiment and simulation is good there-bye validating in this case the particular constitutive equation, constitutive parameters and also the numerical simulation used.

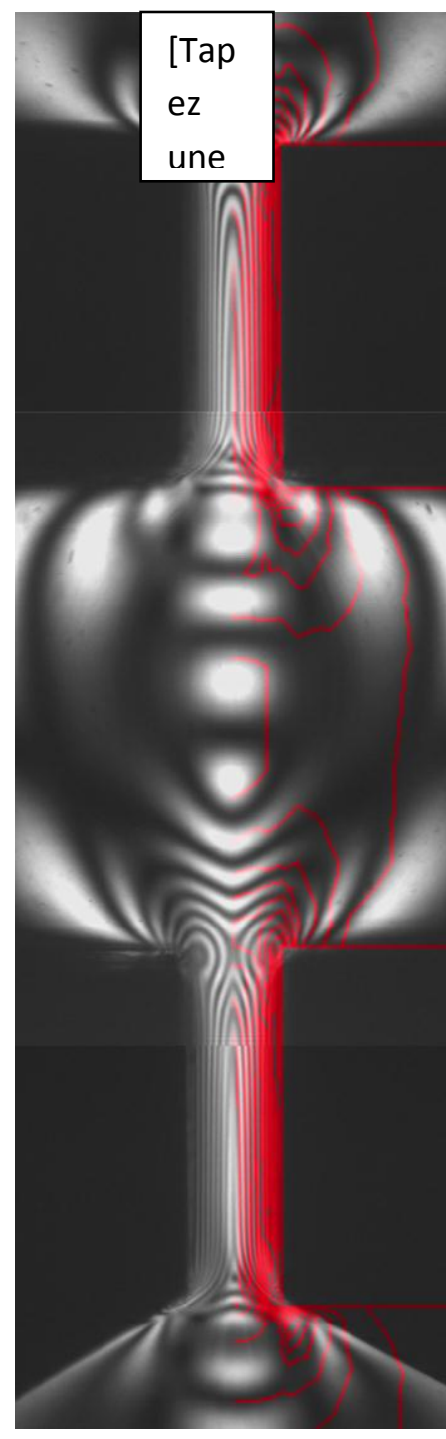

(1)

Figure 4: Double-cavity flow birefringence patterns of a Linear low density polyethylene mLLDPE at a temperature, $190^{\circ} \mathrm{C}$ and flow rate $33.9 \mathrm{~mm}^{3} \mathrm{~s}^{-1}$, (apparent wall shear rate in the slit $\sim 44 \mathrm{~s}^{-1}$ ). Flow is from top to bottom. Comparison of the overall experimental flow birefringence pattern with the simulated PSD (the right hand figure). The increment of PSD contour lines is $2.95 \times 10^{4} \mathrm{~Pa}\left(\right.$ SOC, $\left.1.74 \times 10^{-9} \mathrm{~Pa}^{-1}\right)($ Lee and Mackley, 2001).

As seen, the Wagner model simulations captured the fringe pattern at cavity 1 (mushroom shape) and cavity 2 (butterfly shape). 
A further example of fitting simulation to MPR experimental data is given in Figure 5. In this example the experimental differential pressure trace is compared with both a compressible and incompressible multi mode differential Rolie-Poly constitutive equation (Valette et al., 2006). In this case it can be seen that the time dependant pressure relaxation is more accurately simulated with the incorporation of compressibility.
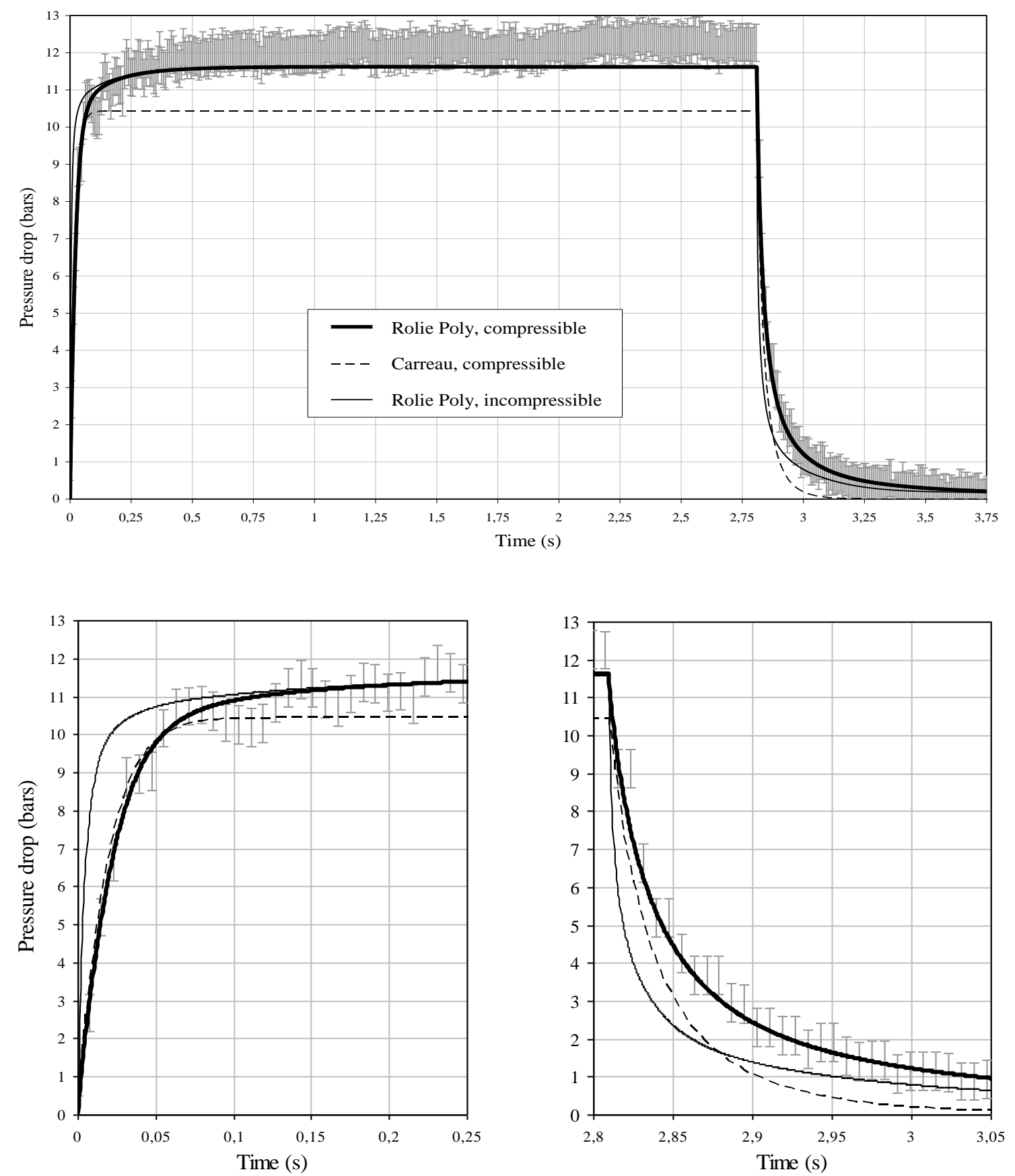

Figure 5: Time dependent pressure difference profile on the MPR rheometer, Linear low density polyethylene LLDPE at $185{ }^{\circ} \mathrm{C}$ at a piston speed of $5 \mathrm{~mm} / \mathrm{s}$, complete curve (top) and details of start-up (bottom left) and relaxation (bottom right) flow. Experimental data (error bar I ), compressible Carreau ( - - ), incompressible Rolie Poly ( - ) and compressible Rolie Poly ( - ). (Valette et al., 2006) 


\subsection{Smooth convergent flow}

It is also possible to use laboratory prototype flows as a way of determining non linear parameters of a viscoelastic constitutive equation (for example Ianniruberto and Marruci model, equation 3) using both flow birefringence (figure 7) and laser doppler velocimetry measurements (figure 6). An "inverse" procedure was adopted where the initially unknown non linear parameters of the model were adjusted using the simulation in order to fit the experimental data (figure 8) (Boukellal et al., 2011).

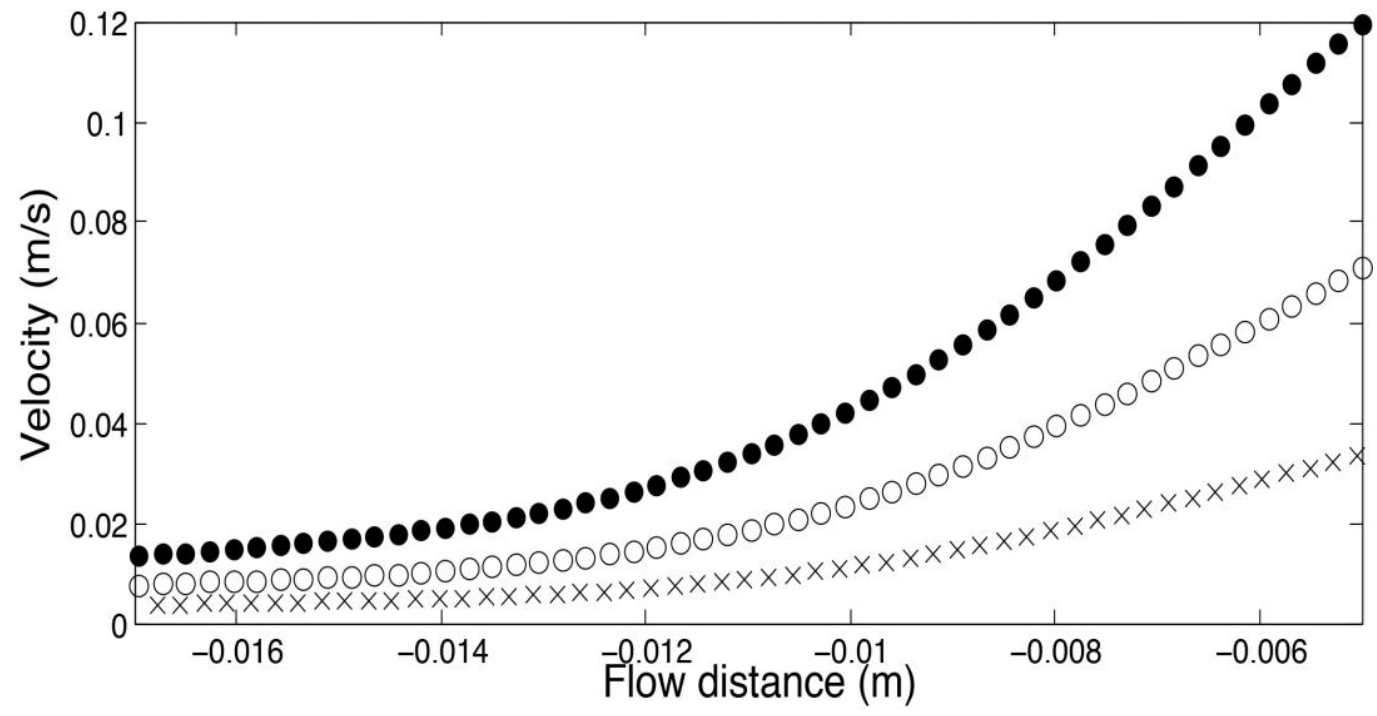

Figure 6 : Polystyrene in a convergent flow geometry (see figure 7):laser doppler velocity measurements along symmetry axis for three different flow rates; from the bottom: $0.25 \mathrm{~cm}^{3} / \mathrm{s}$, $0.45 \mathrm{~cm}^{3} / \mathrm{s}, 0.70 \mathrm{~cm}^{3} / \mathrm{s}$.

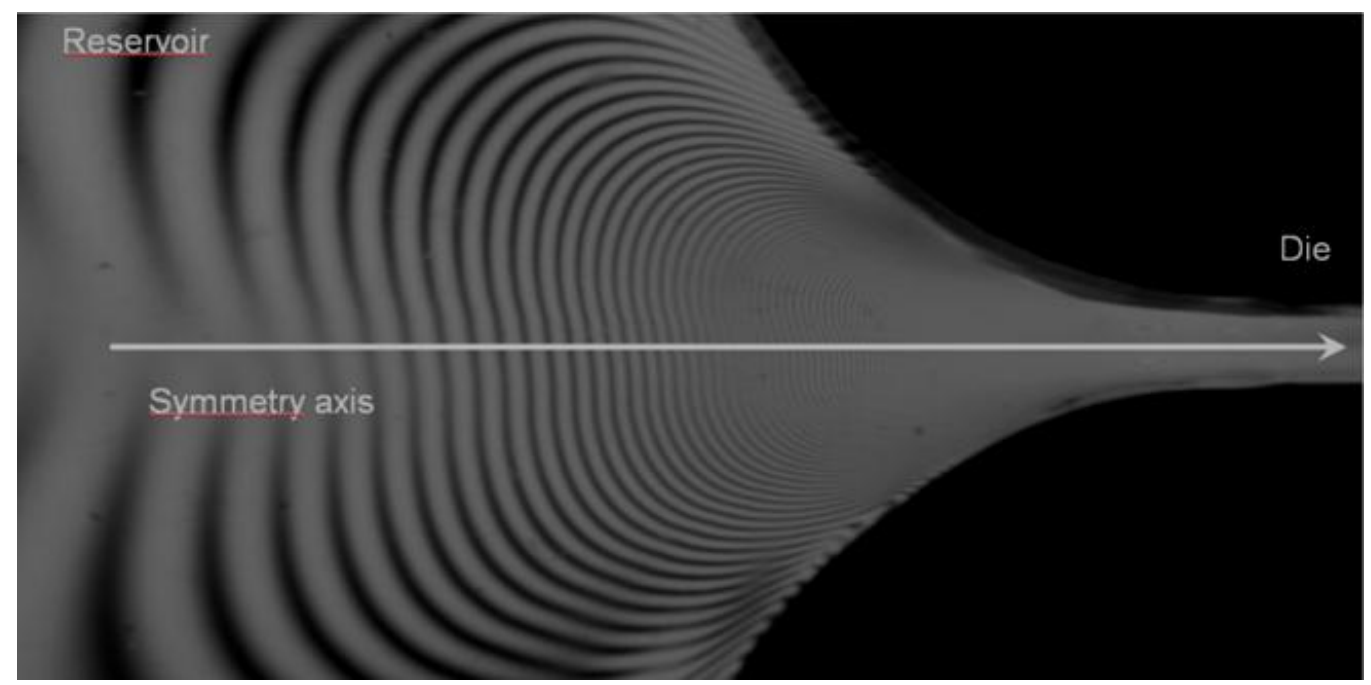

Figure 7: flow birefringence pattern, Polystyrene, flow rate $Q=0.25 \mathrm{~cm}^{3} / \mathrm{s}$ 


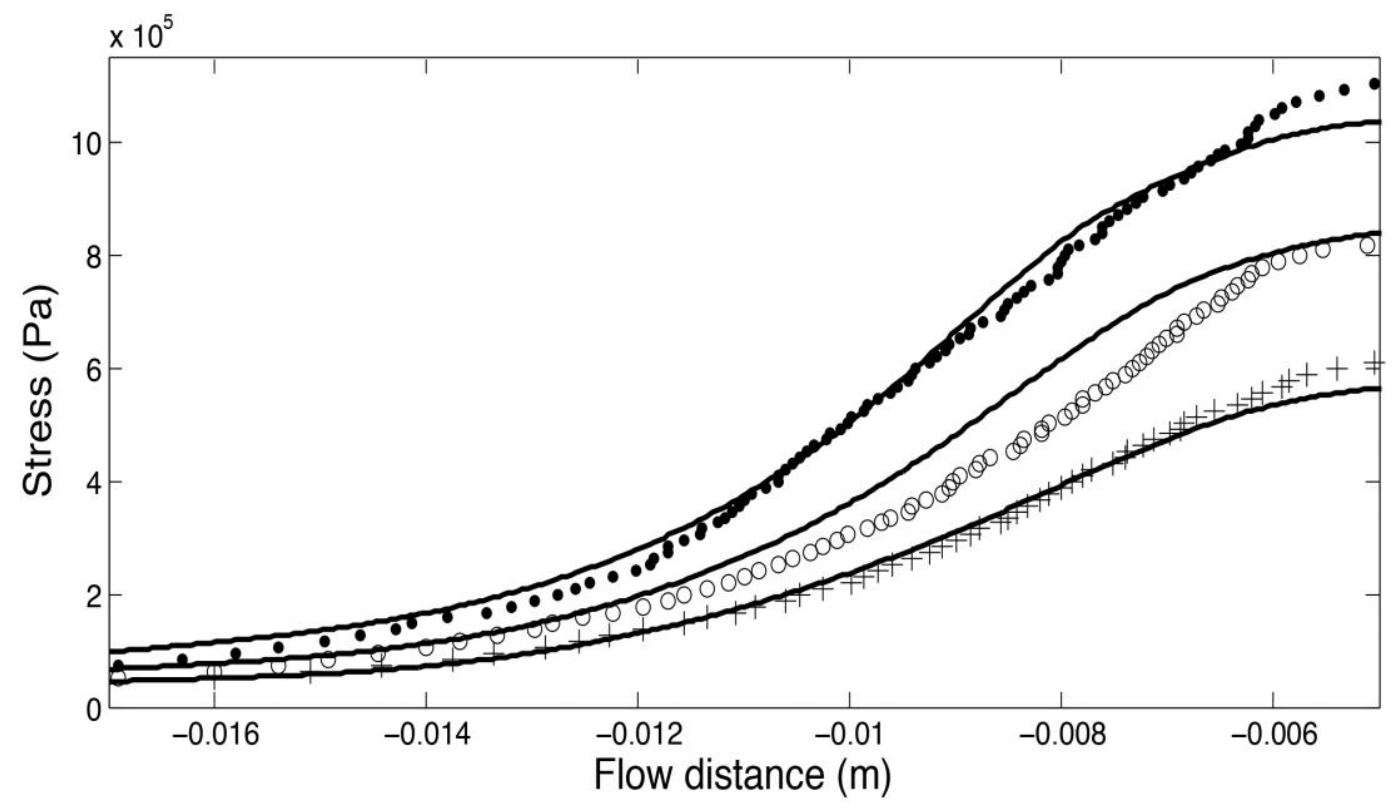

Figure 8: Comparison between the principal stress difference calculated on the convergent flow symmetry axis (derived from the velocity measurements of Figure 6 and the MarrucciIaniruberto constitutive equation; full lines) and those deduced from birefringence patterns; points (Figure 7). The data are the same as in Figure 6.

In all the above cases there has been a successful fit between experiment and simulation and this helps provide confidence that at least for isothermal homogeneous polymer melt flow various simulation strategies using a range of different constitutive equations can give a reasonably accurate description of events.

\section{Some industrial flow geometries}

In the following section a number of commercial polymer processes are selected in order to demonstrate different features of simplifications and complexities that can arise when attempting to model polymer melt processing.

\subsection{Fiber spinning}

One of the simplest polymer processing geometries is fiber spinning shown schematically in Figure 9. But as mentioned in section $3.2 \mathrm{c}$ in order to correctly model fiber spinning it is necessary to use a viscoelastic constitutive equations in the models to account for significant elongation behavior (Gagon and Denn, 1981; Papanastasiou et al., 1987; Gou and McHugh, 2003). In addition, as soon as the spinning distance is large, thermal phenomena are dominant and a specific attention needs to be paid to the crystallization of the polymer and its influence on the rheology of the polymer and the temperature balance equation (Jarecki and Ziabicki, 2004). Gravity forces cannot also be neglected for long stretching distances and the high spinning velocity can also require accounting for inertia terms as well as friction with the surrounding air.

In what follows, fiber spinning of a High Density Polyethylene over a short distance between a spinneret and a water bath (where it will be quenched) is considered. Thermal phenomena as well as gravity and inertia are neglected for this particular problem.

In order to simplify the calculation, the geometry of the stretching path can be divided in successive slabs. Starting from the known extrusion velocity, filament diameter and 
elongation stress at die exit, the mass and stress balance equations are solved slab after slab until the extremity of the stretching path is reached. If the final velocity at take up is different from the prescribed drawing velocity, the unknown stretching stress is adjusted by a shooting method until convergence is achieved.

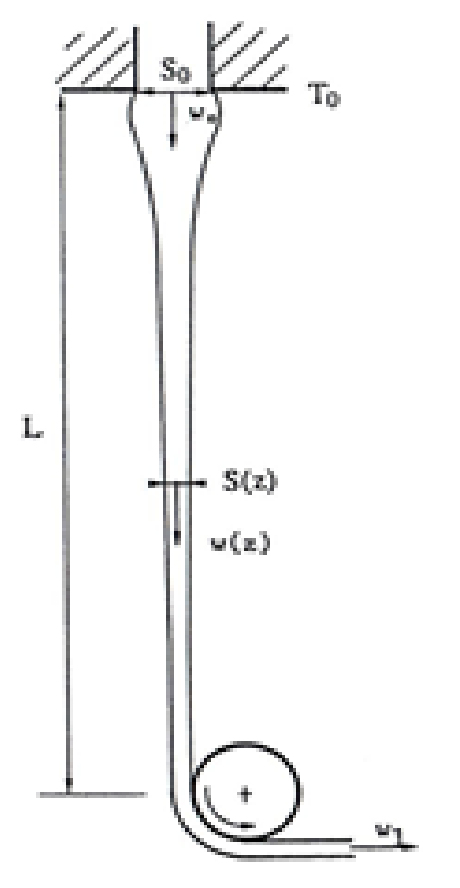

Figure 9: Typical geometry of mono-filament fiber spinning

Figure 10a shows a simulated velocity profile along the stretching path for different values of the Deborah number (see section 3.2c). In the Newtonian case an exponential velocity profile is observed however the curves becomes linear with increasing Deborah number using a simple Maxwell model which is then able to capture the experimental fiber diameter evolution along the stretching distance (Figure 10b).
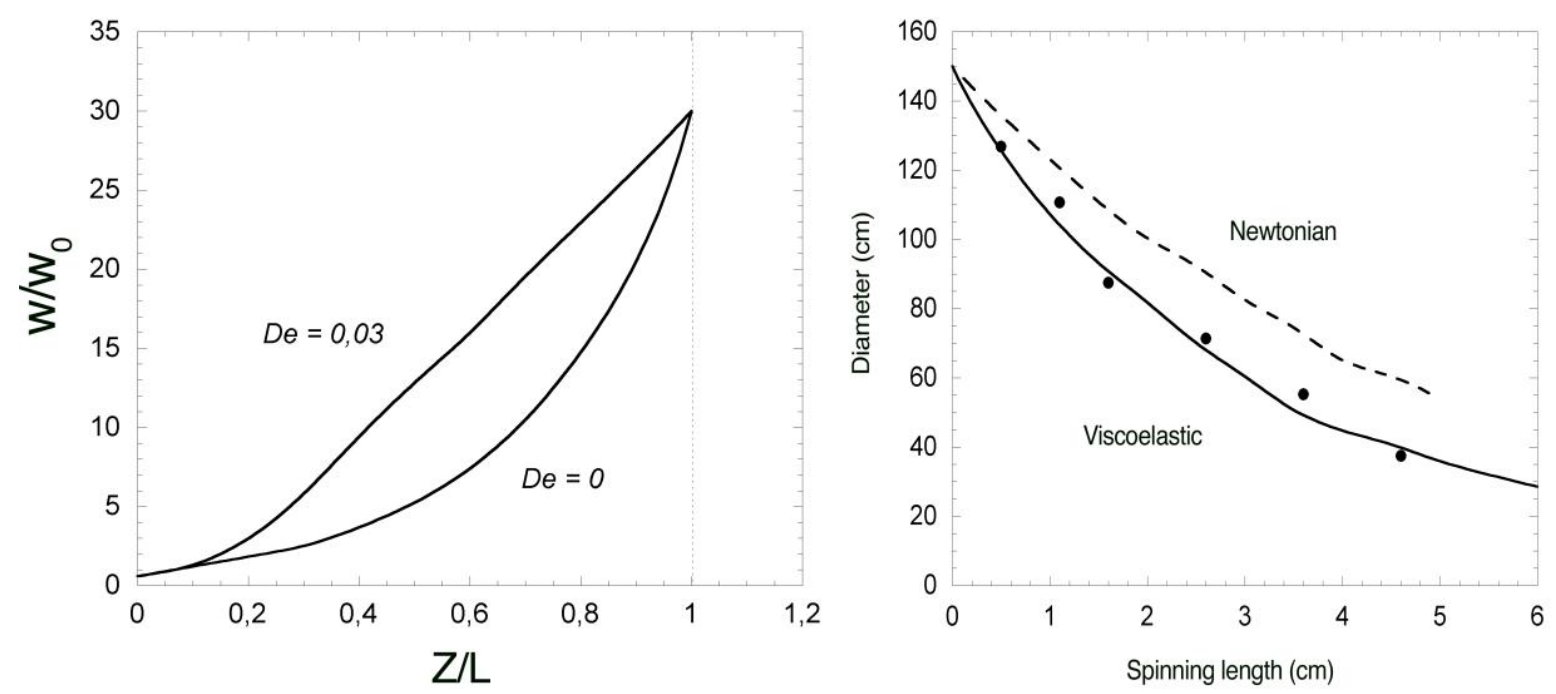

Figure 10: (a) velocity profile along the stretching path in the Newtonian case (De=0) and in the viscoelastic case (De=0.03); (b) filament diameter along the stretching path; (•) experimental measurement, (---) Newtonian result, (_ Viscoelastic result (De=0.016). The Draw ratio Dr=100 (Demay, 1983). 


\subsection{Optimization of a film-blowing die}

A film-blowing die must provide a uniform flow and temperature distribution around the circumference of the die and any thickness and temperature heterogeneity would be enhanced in the subsequent film blowing process leading to unacceptable film properties. The geometry of a film-blowing die is therefore complex as shown schematically in Figure 11a. Molten polymer delivered by the extruder is distributed into different radial channels ( 4 in figure 11b) that open into helical channels machined into the central mandrel. The clearance between the mandrel and the axisymmetric die shaft is gradually increased in the vertical direction (Figure 11c), thus ensuring a homogeneous distribution of the polymer at the die outlet, independent on the position of the radial channels.

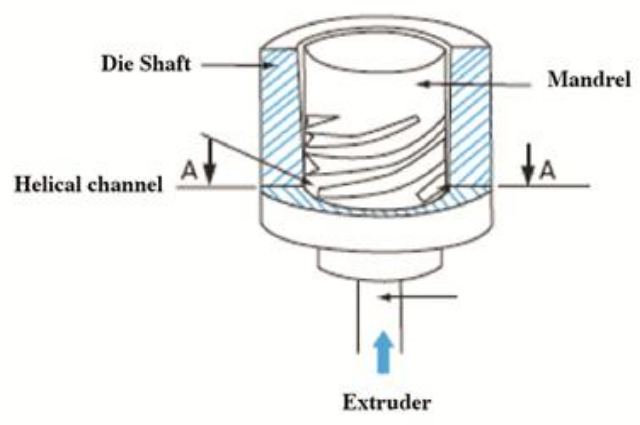

(a)

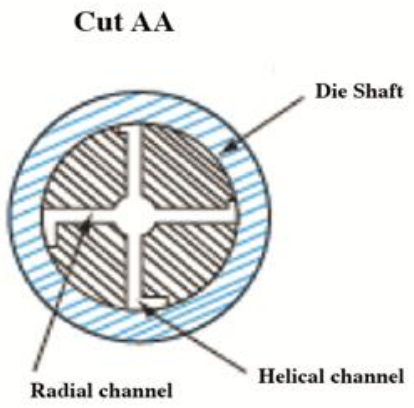

(b)

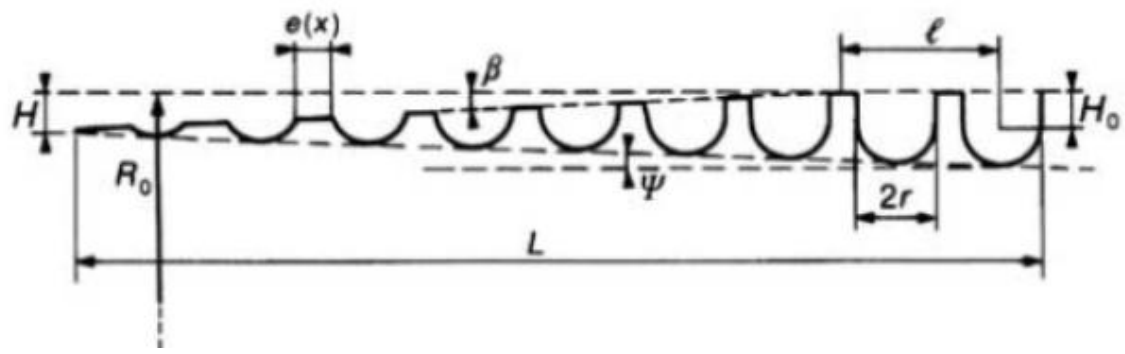

(c)

Figure 11: Geometry of a film-blowing die: (a) overall view, (b) cut in the plane AA, (c) cut in the vertical plane

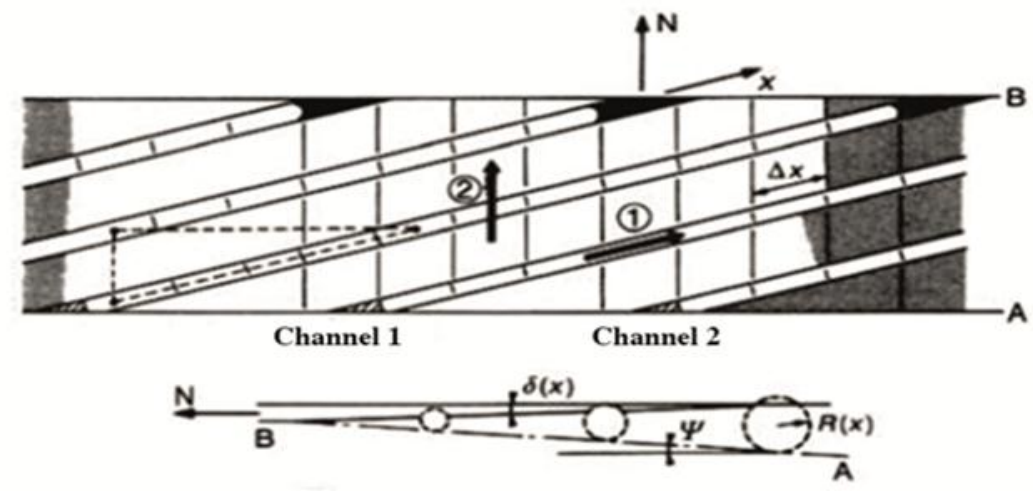

Figure 12: film-blowing die; equivalent unrolled geometry (top) and vertical cut (bottom) (Vergnes and Agassant, 2008) 
The use of a direct numerical method would require a refined mesh, especially between the die shaft and the top restrictions between two successive helical channels and this will result in significant meshing sizing. Moreover, the number of geometrical parameters that can be varied will induce a very expensive parametric study. Much simpler modeling can be achieved by unrolling the flow between the central mandrel and the axisymmetric die shaft and by schematizing the flow in helical channels by tube Poiseuille flows and the flow above the restrictions between two successive channels by plane Poiseuille flows, and then writing local flow and pressure balances on local finite volumes (Figure 12) ( see for example Saillard et al 1984). By using this method, Figure 13 shows for example the influence of a modification of the initial flow length without leakage 1 or on the initial channel depth $\mathrm{H}_{0}$ on the final flow rate distribution output (see Figure 11c).

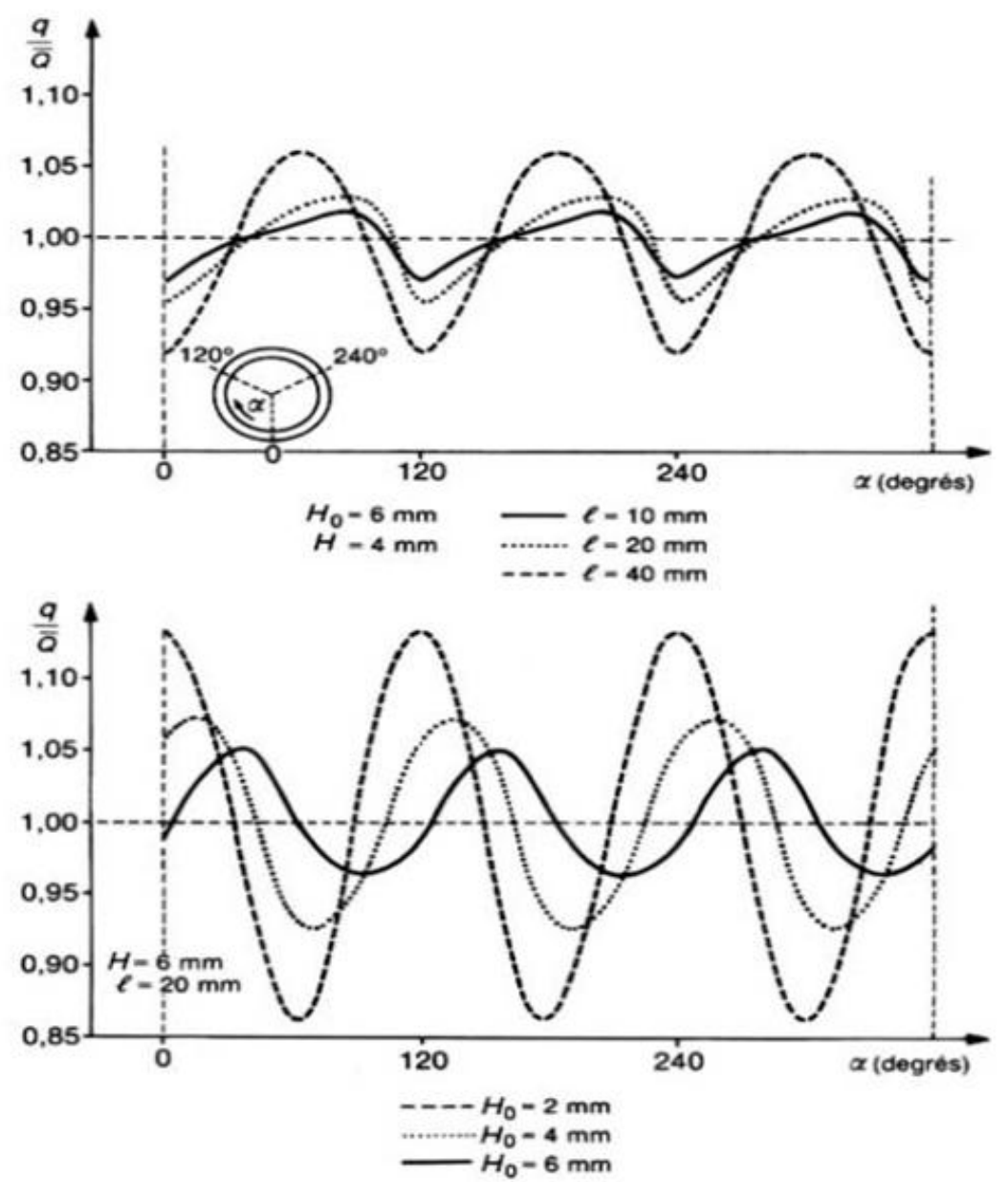

Figure 13: Influence of some geometrical parameters on the polymer flow distribution at film-blowing die exit. (top) initial length without leakage, (bottom) initial depth of the channel. $q$ is the local flow along the circumference of the die, $\bar{Q}$ is the average flow rate (Agassant and Vergnes, 2008).

Thermal phenomena can significantly influence the polymer flow distribution however the difficulty is to define the most realistic boundary conditions. An average temperature calculation is presented here assuming adiabatic conditions along the mandrel and isothermal conditions along the die shaft. The coupling between mechanical and thermal resolution is carried out iteratively on the whole flow domain. Figure 14 shows that the outlet temperature will depend on the regulation temperature of the die, but also that flow homogeneity is 
improved by increasing this die temperature. However, a too high die exit temperature will make the subsequent polymer blowing step more difficult.

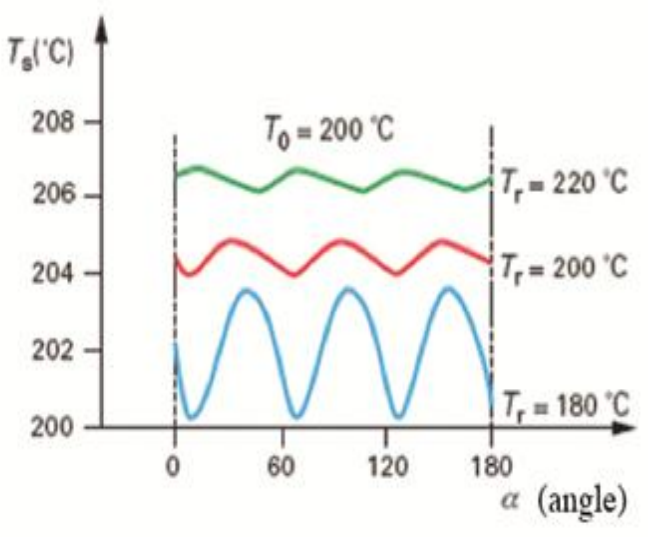

(a)

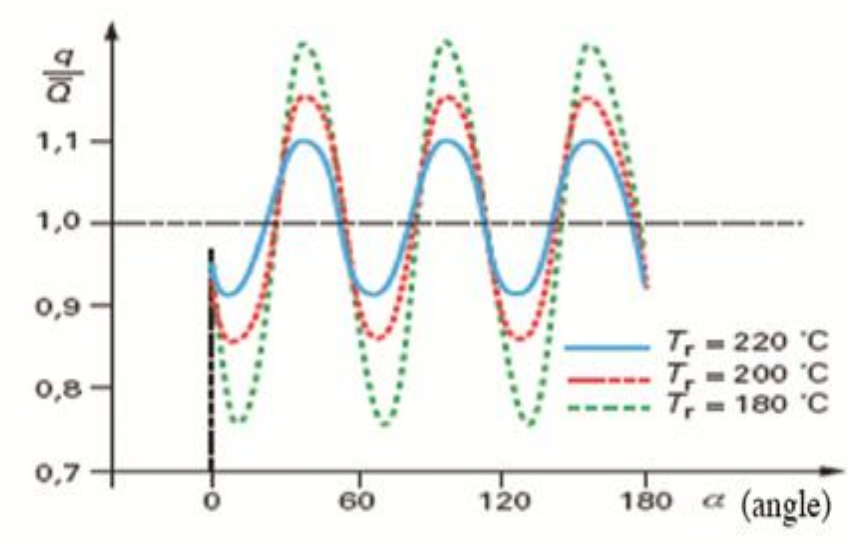

(b)

Figure 14: The influence of the die regulation temperature on the distributions of mean temperature (a) and flow (b) at film-blowing die exit (Vergnes and Agassant, 2008)

\subsection{Flat film “coat hanger" die processing}

Flat dies are commonly used to produce sheets or plates. They often have a so-called "coat hanger" geometry (half of this geometry is shown in Figure 15): the molten polymer flows from the extruder into a channel of variable cross section, the "coat hanger "(a), which achieves the most uniform distribution possible across the width of the tooling. An adjustable straining bar (c) followed by a relaxation zone with a wider gap (d) allows for correcting any imperfections in the polymer distribution. The final thickness is adjusted using flexible lips (e). The objective is that the coat-hanger die provides the more regular thickness and temperature distribution at die exit at the highest possible output rate.
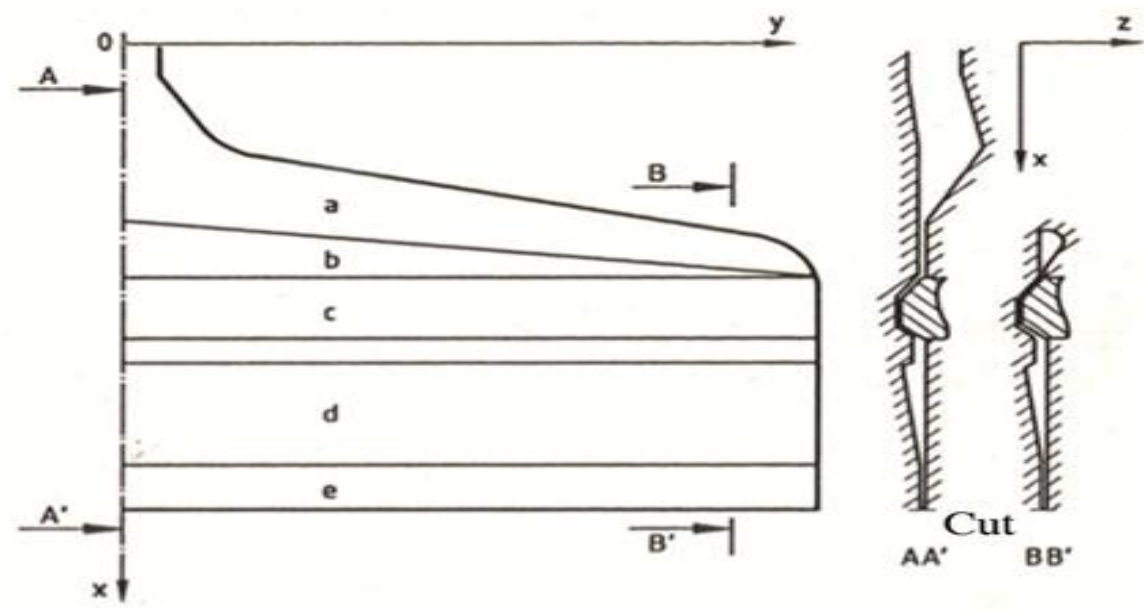

Figure 15: Schematic of a coat-hanger die (for reasons of symmetry, only half is shown) 
Assuming that the flat die can be considered as a "thin layer", Hele-Shaw and average temperature equations presented in section $3.4 \mathrm{c}$ can be used and solved iteratively by finite difference or finite element methods (see for example Vergnes et al, 1984; Arpin et al, 1992 \&1994). In fact 3D computation is straightforward in that case, but it would be not userfriendly for optimization purpose. An optimization procedure could consist in starting from the real 3D geometry and a 3D isothermal computation, then test the Hele-Shaw model with a finite difference or finite difference model and quantify the differences between 3D and HeleShaw results; If these differences were small, further optimisation could be carried out using Hele-Shaw model and when this provided an improved solution, return to the 3D calculation for the final simulation.

Figure 16 shows the streamlines and iso-pressure distributions for a power-law rheological behavior (shear thinning index of 0.35) derived from the Hele-Shaw calculation. The total pressure drop is $10 \mathrm{Mpa}$ and the most significant pressure drop is localized around the straining bar. The streamlines follow first the coat-hanger distribution channel, then pass gradually into the die land area without being influenced in that particular flow situation by the relaxation channel. At die exit, the stream lines are almost equidistant, indicating a very good flow rate distribution.

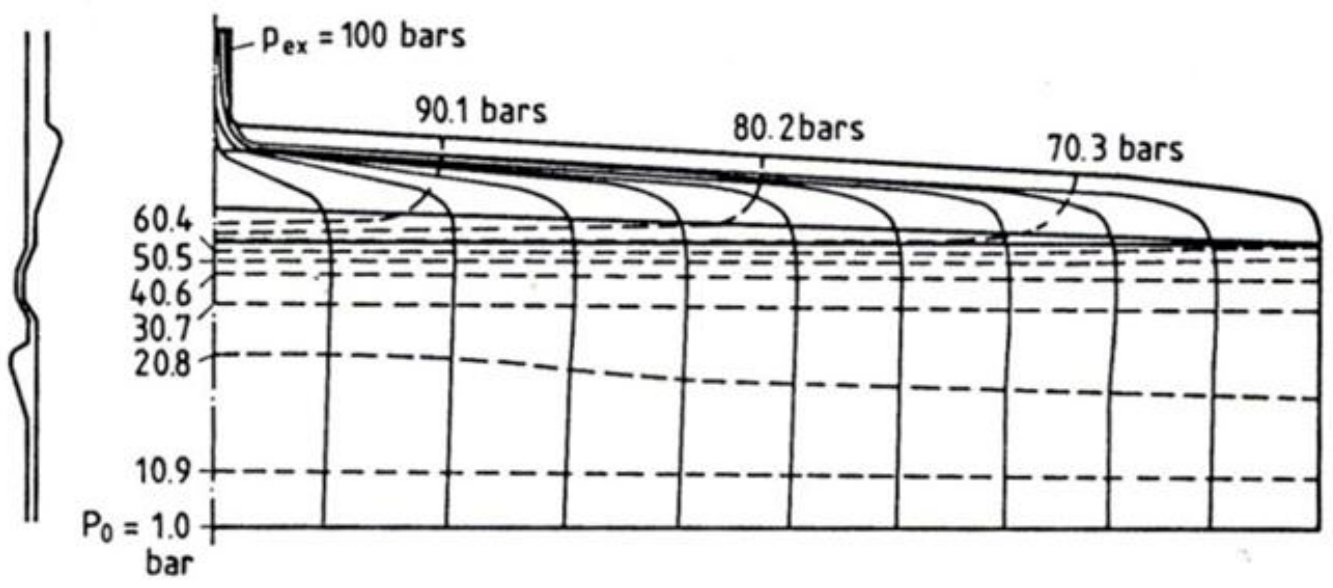

Figure 16: Pressure and flow distribution in a coat-hanger flat die (Vergnes et al.,1980)

This is confirmed in Figure 17, where the ratio of the local flow rate $\mathrm{Q}_{\mathrm{x}}$ on the average flow rate $Q$ has been drawn on the half-width of the die for different values of the shear thinning index.

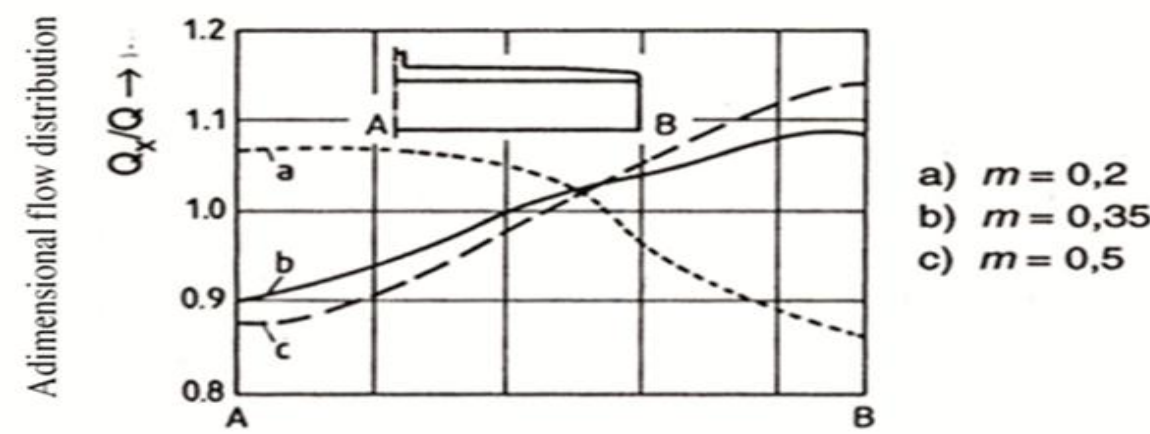

Figure 17: Influence of the power-law index on the flow rate distribution at die exit, $Q_{x}$ is the local flow rate and $Q$ is the average flow rate between $A$ and $B$ (Vergnes et al.,1980) 
For $\mathrm{m}=0.35$ this distribution is satisfactory (within 10\%) and can be then perfectly adjusted with the staining bar and the flexible lips. This distribution is strongly dependent on the power-law index: for $\mathrm{m}=0.2$ the largest local flows are recorded in the center of the die, whereas the opposite phenomenon is observed for $m=0.5$. The oversimplified approaches which consist in optimizing the geometry of a die for a Newtonian behavior, and assuming that this will remain true for any rheological behavior, are therefore dangerous.

The average temperature distribution (which means the average temperature in the thickness at each point of figure 15) is presented on figure 18 when the inlet temperature of the polymer and the temperature control of the die are identical and equal to $200^{\circ} \mathrm{C}$. There is a very small increase in the average temperature along the flow and a very good homogeneity of temperature at the die outlet. Under the processing conditions chosen, the flow is weakly dissipative and the polymer temperature is controlled by heat conduction from the die walls. It is therefore interesting to calculate the influence of modifying the control temperature of the die, all other processing parameters being equal (Figure 19). There is a clear flow distribution improvement at $220^{\circ} \mathrm{C}$ and a marked deterioration at $180^{\circ} \mathrm{C}$.
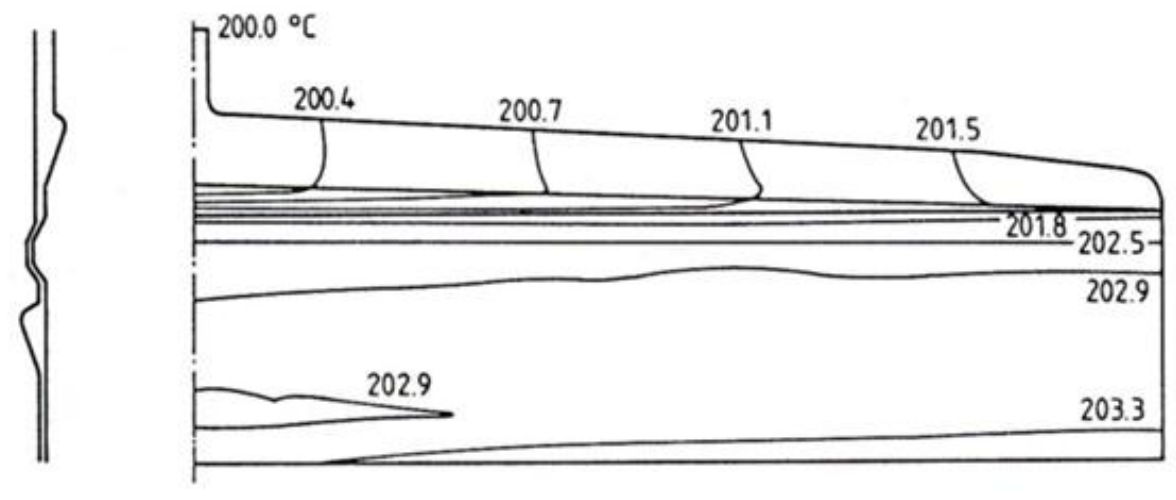

Figure 18: Average temperature distribution in the coat-hanger flat die (initial temperature $=$ regulation temperature of the die $\left.=200^{\circ} \mathrm{C}\right)($ Vergnes et al., 1980)

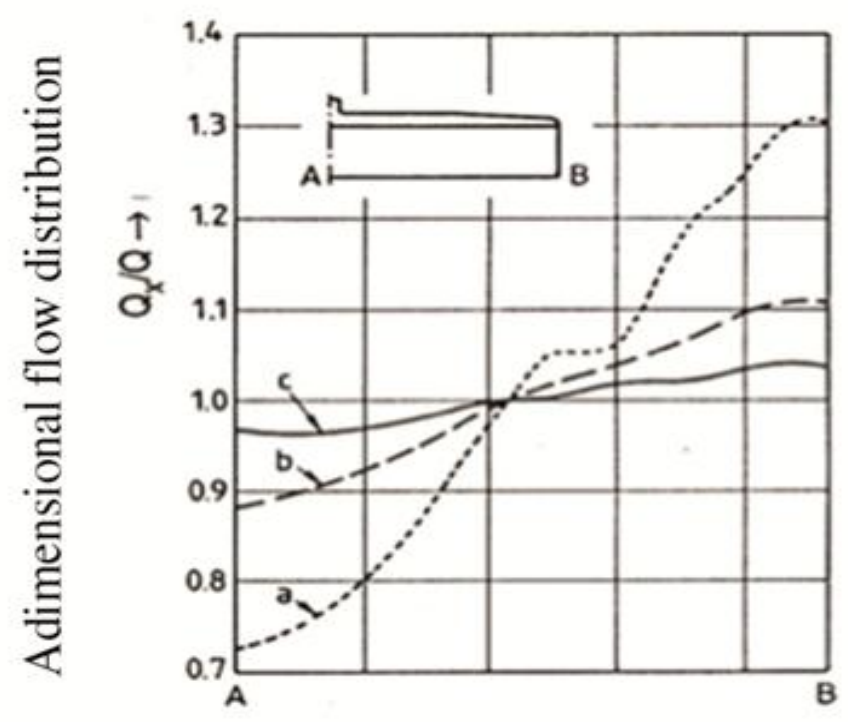

Die temperature

a) $T=180^{\circ} \mathrm{C}$

b) $\mathrm{T}=200^{\circ} \mathrm{C}$

c) $\mathrm{T}=220^{\circ} \mathrm{C}$

Figure 19: Influence of the regulation temperature of the die on the flow distribution (Vergnes et al, 1980) 
This example illustrates clearly the strong coupling between the thermal and the mechanical phenomena and shows that it is preferable to impose a die temperature higher than the inlet temperature of the polymer.

\subsection{Extrusion profile dies}

The design of a profile die is a difficult problem where a main objective is to provide an output speed (and temperature) which is uniform across the whole profile, so that the extrudate does not distort at the die outlet. This is the so-called "balancing" of the profile. Early modelling used 1D simplified calculations along independent flow paths which were then connected using "network" approaches (Huneault et al, 1996). Later 2D finite element calculations in successive slices were then linked together using a slab method (see section 5.1) ( D'Halewyn, 1992; Hurez et al., 1993; Carneiro et al., 2001). In fact, looking at the geometry of even a simple profile such as shown in Figure 20 means that a threedimensional finite element approach seems inevitable in most cases. (Gonçalves et al., 2013).

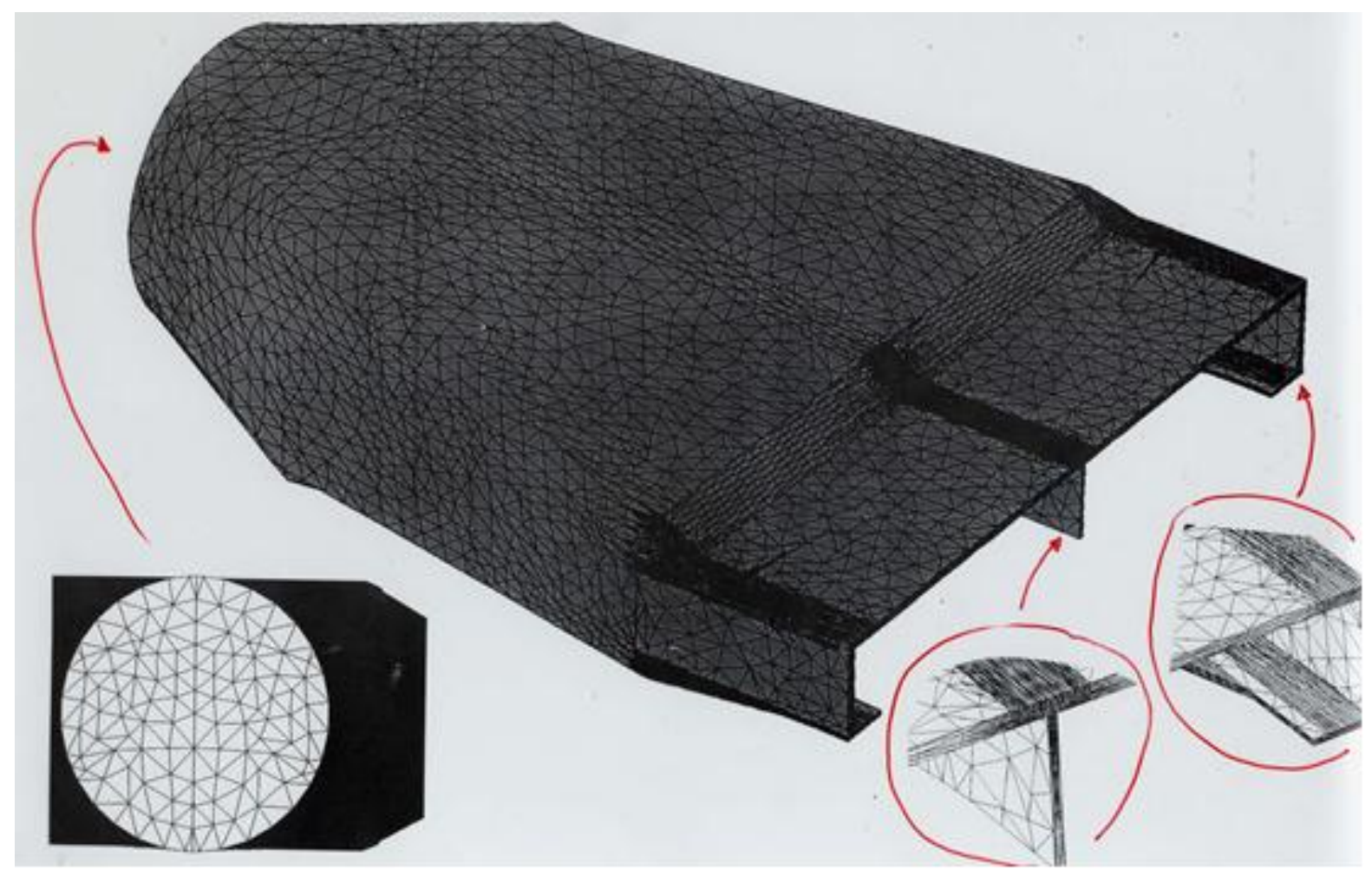

Figure 20: Anisotropic meshing of a profile die

Given the large reduction in section between the inlet and the outlet of the die (a factor hundred or more), and the requirement of a sufficient number of finite elements in the final thickness of the flow, a homogeneous meshing of the flow volume would cause prohibitive calculation times to solve systems of equations with tens of millions of unknowns. Even if the development of parallel computing makes it possible now to solve such problems, the use of anisotropic meshes (refined in the thickness of the flow and "de-refined" in other dimensions), coupled with an adaptation of the mesh size according to the local dimensions of the flow and optimized numerical methods, provides interesting results in a reasonable computation time (Gruau and Coupez, 2005). Figure 21 shows successive phases of optimizing the geometry of a profile die to obtain an output rate as homogeneous as possible. 


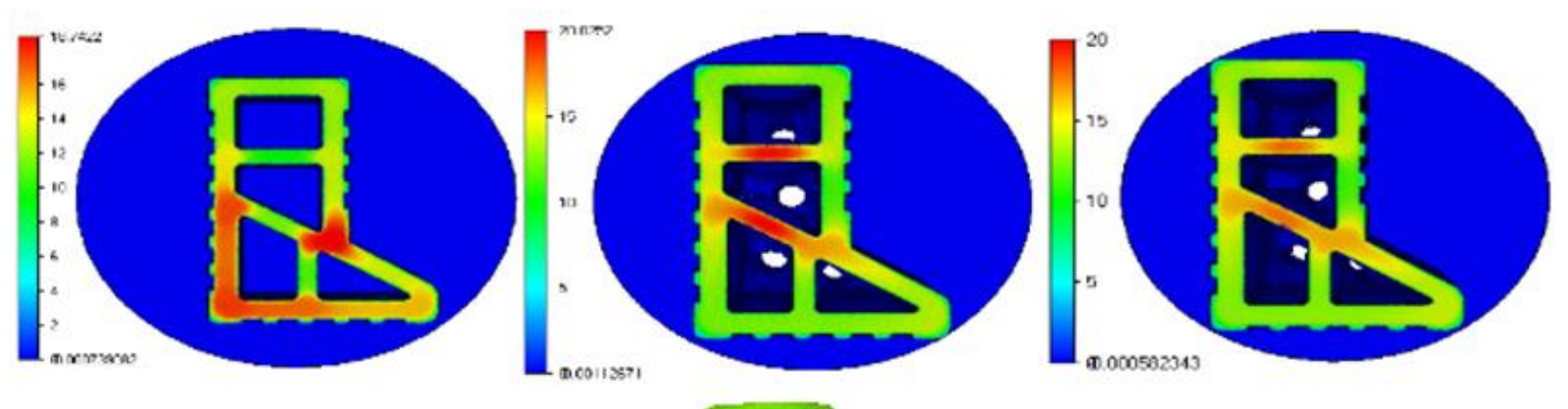

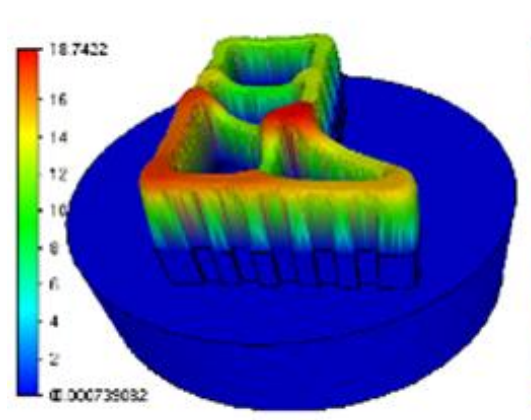

(a)

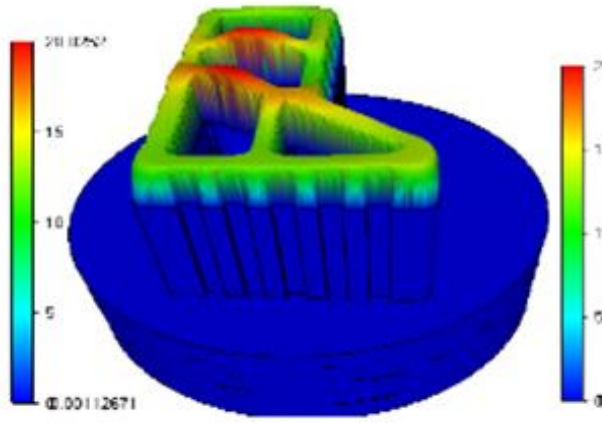

(b)

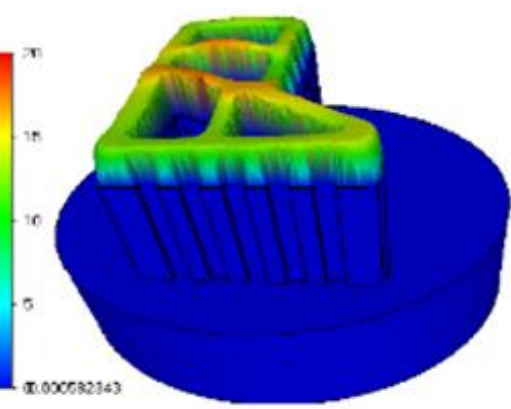

(c)

Figure 21: Example of a profile die 3D calculation; balancing of the final velocity field by modifying the geometry of the upstream zones; (a) initial geometry, (b) the first test, $(c)$ the second test; velocity field in the final section:(up) top view, (bottom) perspective view, power-law viscous behavior (Foudrinier, 2007; Vergnes and Agassant, 2008)

\subsection{Injection moulding}

It is in the area of injection molding that the first polymer processing numerical simulation software in the mid-1980s was developed. In that case the purpose was not to optimize the shape of the plastic part but to optimize the filling of the mold. If this can be achieved by modeling, the mold itself can be designed (especially the location of injection gates and venting ports) to give optimum filling before the actual mold is manufactured. The objective is to fill the cavity as uniformly as possible (that is to say such as the ends of the mold cavity are reached at equivalent filling times), at a temperature as constant as possible (i.e. in conditions where the viscous energy dissipation is roughly balanced by heat conduction to the walls, which means with a local Brinkman number equal to unity). A key problem is to predict the location of weld lines in such a way that they are not visible from the outside and submitted to low stresses during the life time of the plastic part. This cavity filling optimization in highly non-isothermal conditions is now properly resolved by many commercial software using purely viscous temperature dependent behavior.

Often commercial software assumes the mold to be a "thin layer" and then use the Hele Shaw approximations. This type of approach, commonly named 2.5D, was introduced by Kamal et al. (1975), Hieber and Shen (1980), Wang et al. (1986), Willien (1992). The average temperature approximation is not necessarily consistent given the important temperature gradient between the molten polymer and the mold walls. This requires coupling the mechanical and thermal equations everywhere in the cavity. Moreover this "thin layer" approximation is not able to capture the "fountain flow" effect at flow front (Castro and Macosko, 1982; Mavridis et al., 1986). In order to capture such phenomena and to account for complex mold geometry as the one presented figure 3, 3D modeling is required. Viscous 
incompressible temperature dependent models have been first developed (Pichelin and Coupez, 1998 ; Hétu et al., 1998; Kim and Turng, 2004) and then generalized to account for compressibility (Haagh et al., 2001; Silva et al., 2005). Figure 22 shows successive steps of the filling of the cavity where the meshing has been shown in Figure 3.
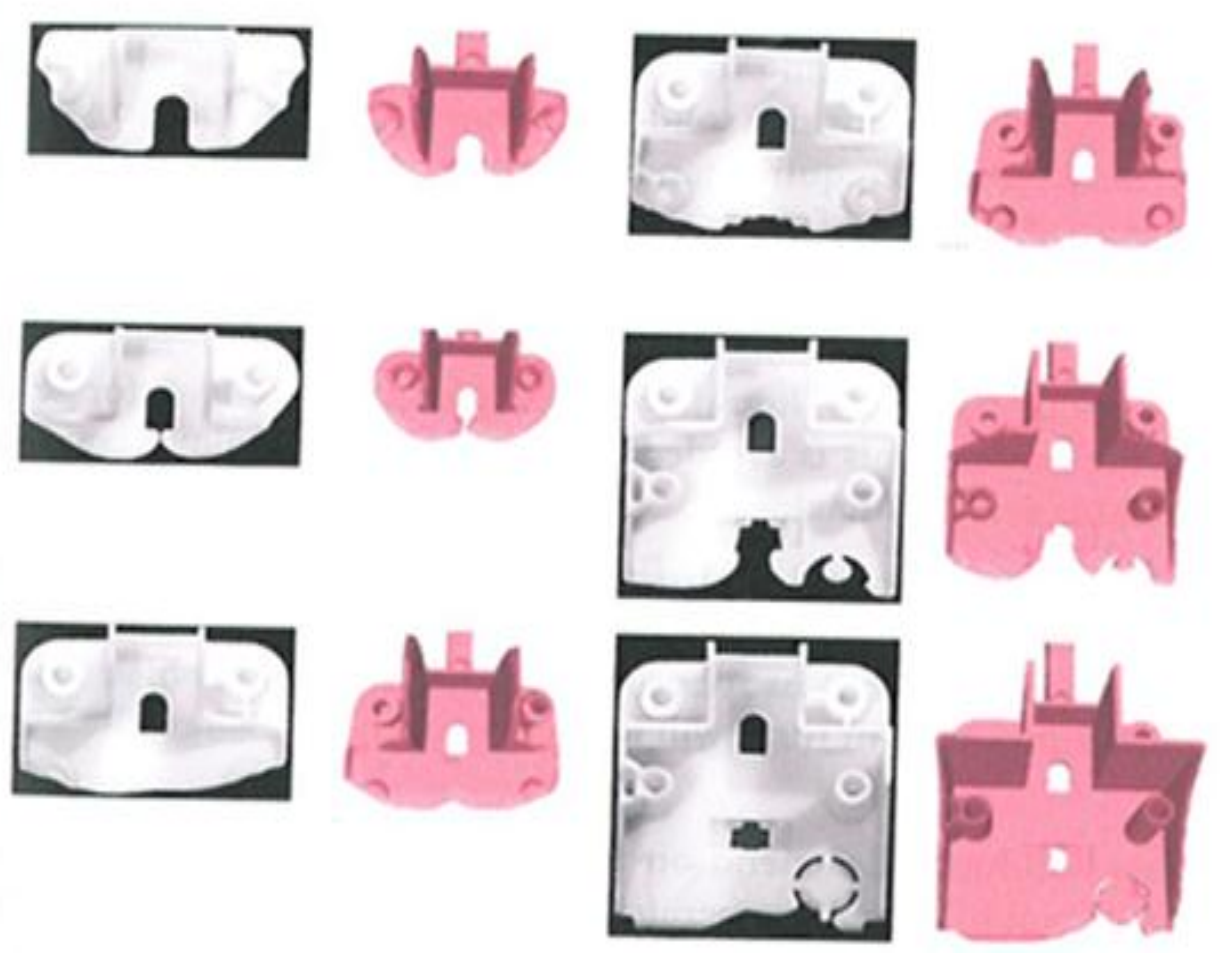

Figure 22: Computed (on the right in each column) and experimental (on the left in each column) short shots for the filling of the cavity presented Figure 2. The polymer is a polystyrene (Silva et al., 2009).

Nowadays the question in injection molding is not only to fill the mold in appropriate conditions, but also to predict the shape and the properties of the produced plastic part that is to say to master:

- $\quad$ The packing stage, which consists in feeding the cavity already filled with additional molten polymer to compensate for the variation in specific volume due to temperature and pressure decrease. This requires introducing compressibility in the balance equations (mass, mechanical and thermal), and introducing relevant data for the dependence of the density as a function of temperature and pressure. Measuring and modeling rheology around the Glass transition temperature for amorphous polymer and in the crystallization range for semicrystalline polymers remains a challenge and this explains using a mysterious "no flow temperature" in commercial software which is just a fitting parameter. The early models have been applied to simple plaque or disk geometries (Kamal and Kenig, 1972; Huilier et al., 1988; Titomanlio et al., 1988) then generalized to Hele-Shaw models (Chiang et al., 1991, Kabanemi, 1991) and to 3D models (Silva et al., 2009).

- $\quad$ The solidification stage, which starts during the filling phase and continues during the packing phase for semi-crystalline polymers, requires measuring the crystallization temperature as a function of the cooling rate (which is obviously very high near the mold wall) and the flow conditions. During this phase, residual stresses develop and lead to the deformation of the plastic part at the mold's opening and thus result in final dimensions being 
different from those of the mold cavity. Purely elastic models have been first developed (Titomanlio et al., 1987; Denizart et al., 1995; Boitout et al., 1995; Farhoudi and Kamal, 1999) followed by more sophisticated solid viscoelastic models (Douven et al.,1995; Kabanemi et al., 1998; Kamal et al., 2002). The accurate prediction of residual stresses and strains remains a challenge.

Figure 23 compares, for the plastic part of figure 3, the calculated and the measured pressure in the mold during the whole injection cycle, including filling, packing and cooling.

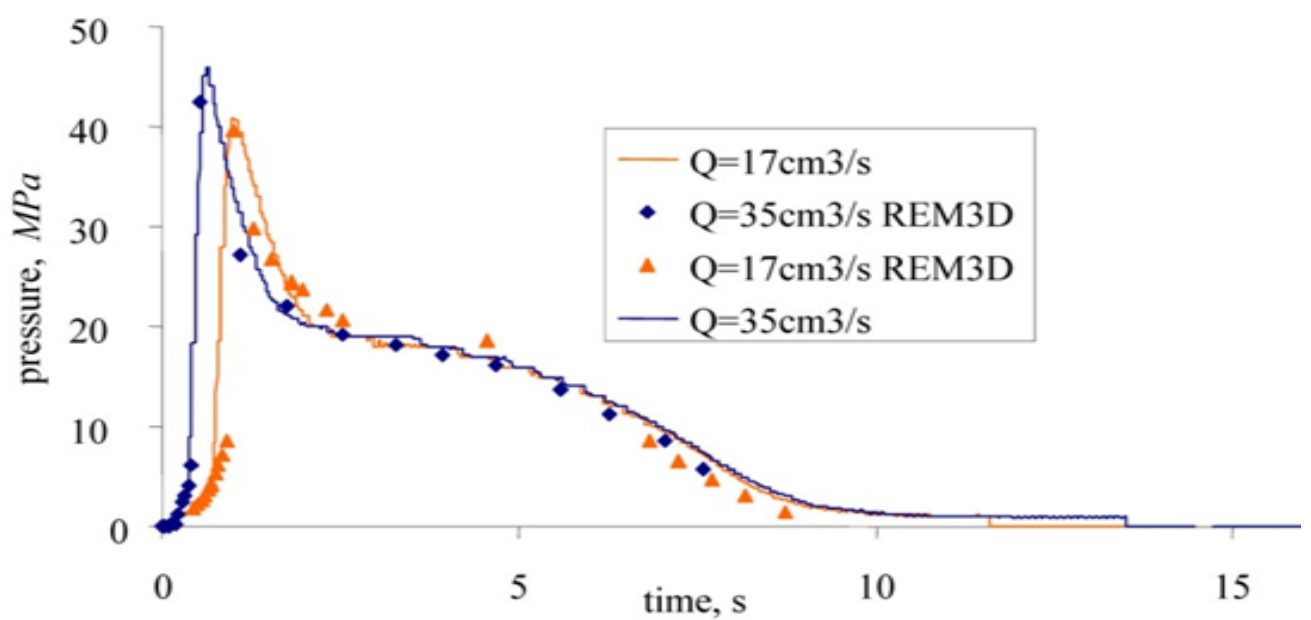

Figure 23: Pressure as a function of time in the cavity of Figure 3 during the entire injection cycle for two different flow rates, the polymer is a polystyrene (Silva et al. 2009).

\subsection{Blow moulding}

The blow-molding process consists of extruding a vertical tube, the parison, pinching it at its base within a cooled mold and then blowing air inside to stretch the hot tube along the cold mold cavity as shown schematically in Figure 24.
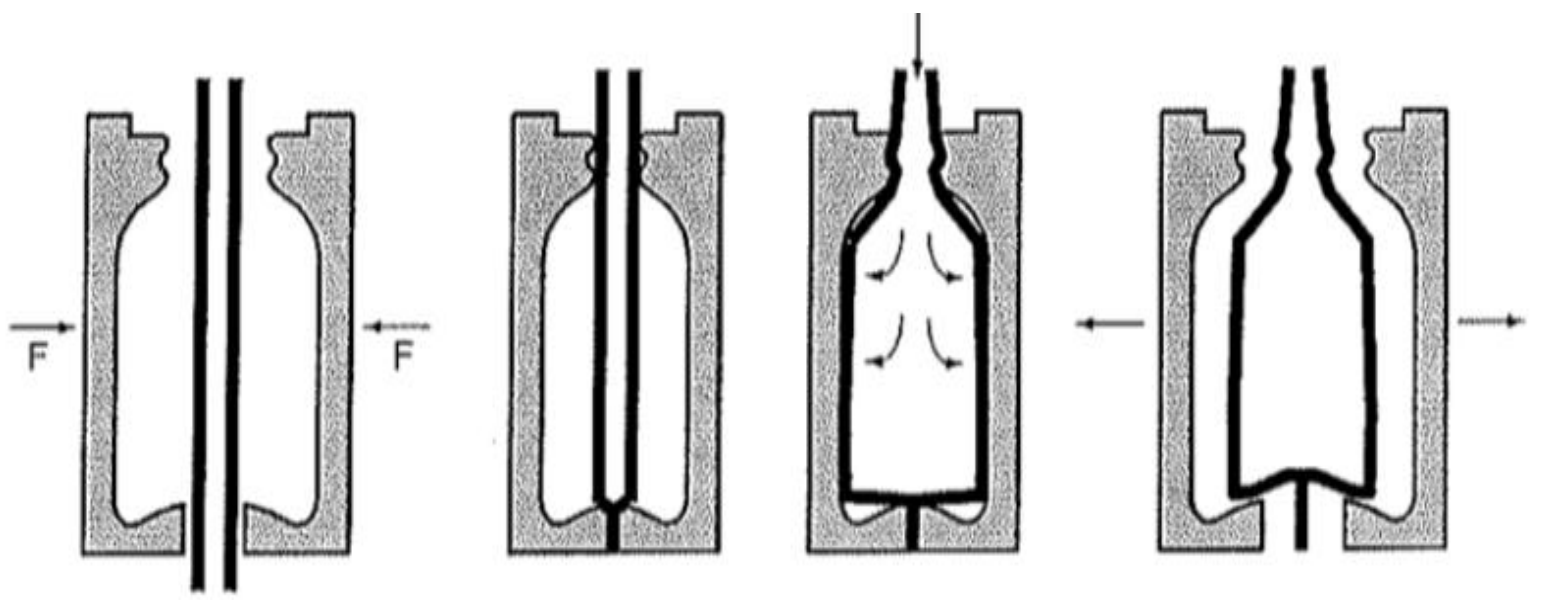

Figure 24: extrusion blow molding process (Agassant and Haudin, 2007) 
The hollow part is solidified along the cold mold wall, then the mold opens, the part is extracted and a new cycle can begin. When manufacturing small hollow bodies (mainly in polyethylene), these operations are performed at high speed in a multi-station mold rotating below the tube die. For bigger parts (automotive tanks, for example), the extruder continuously fills up a pot from which the molten polymer is discharged at regular intervals through a tube die, and the blowing operation is then performed more slowly and in a single mold (Dupont, 2013).

The challenge is to master the thickness distribution of the final hollow body and so to adjust the initial thickness of the tube by "parison programming" (Langkamp and Michaeli, 1996). Most mathematical models use a membrane approach and hyperelastic constitutive equations (De Lorenzi and Nied, 1987) which are suitable for the stretch blow-molding of PET bottles in the rubbery plateau temperature. For the blow molding of Polyethylene which occurs in the molten state, a viscoelastic Maxwell constitutive equation has been used (Rodriguez-Villa et al., 1995).

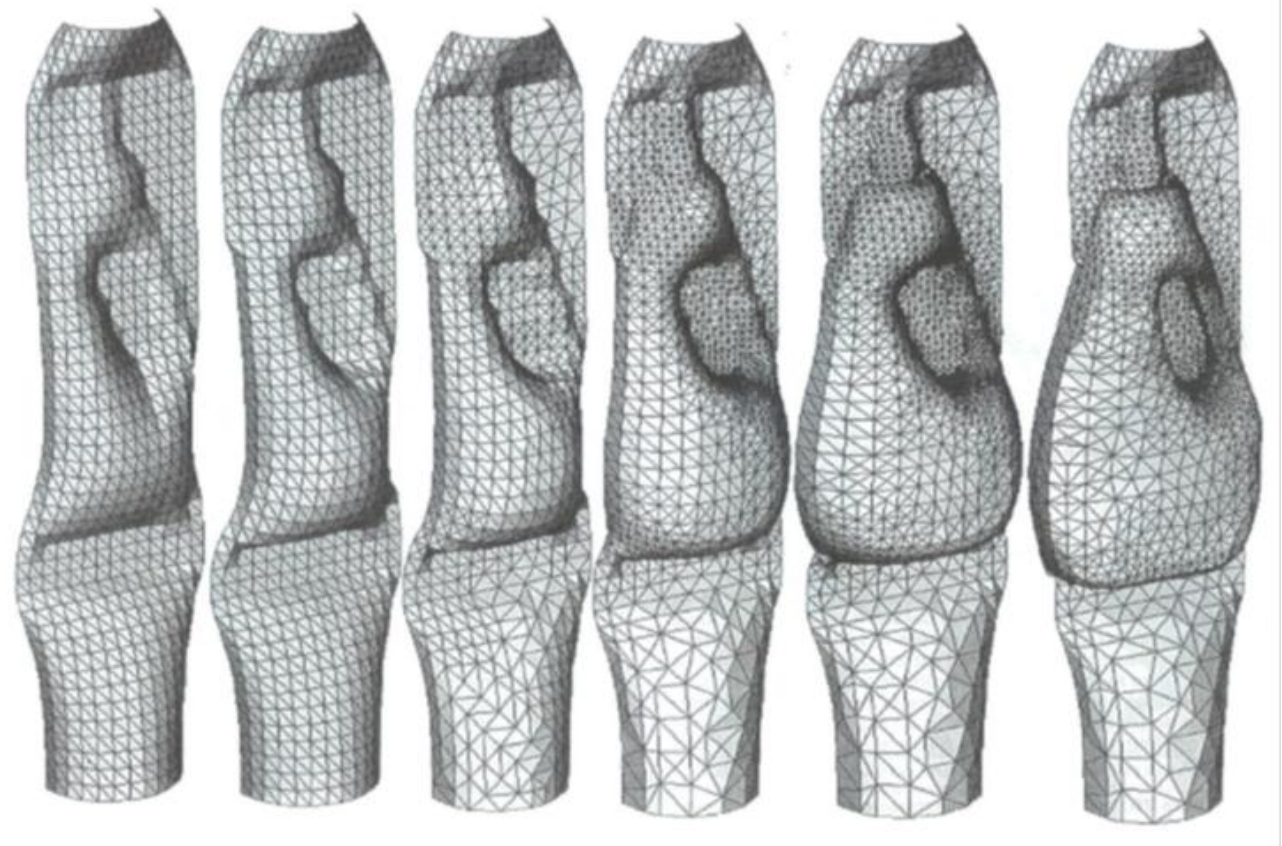

Figure 25: Shape and meshing of the membrane at different steps of simulation of the extrusion - blow molding of a polyethylene shampoo bottle. Successive automatic remeshing may be observed (Bellet et al., 2000)

Successive simulated deformation of the parison during the blowing process are shown in figure 25 as well as the corresponding refinement and coarsening of the mesh surface. This allows mastering the computation time while having a good accuracy in areas that are heavily deformed and/or in the vicinity of the contact with the mold.

Figure 26 presents the final thickness distribution of the bottle: significant overthicknesses are observed at the inner portion of the handle that will be removed later, but also at the middle of the hollow body, which has no justification in terms of mechanical strength. Instead the lower left portion of the hollow body has an insufficient thickness that can cause the bottle breakage in case of falling. The modelling therefore allows optimization of the 
parison shape and, to a lesser extent, the blowing parameters in order to obtain a more appropriate bottle thickness distribution.
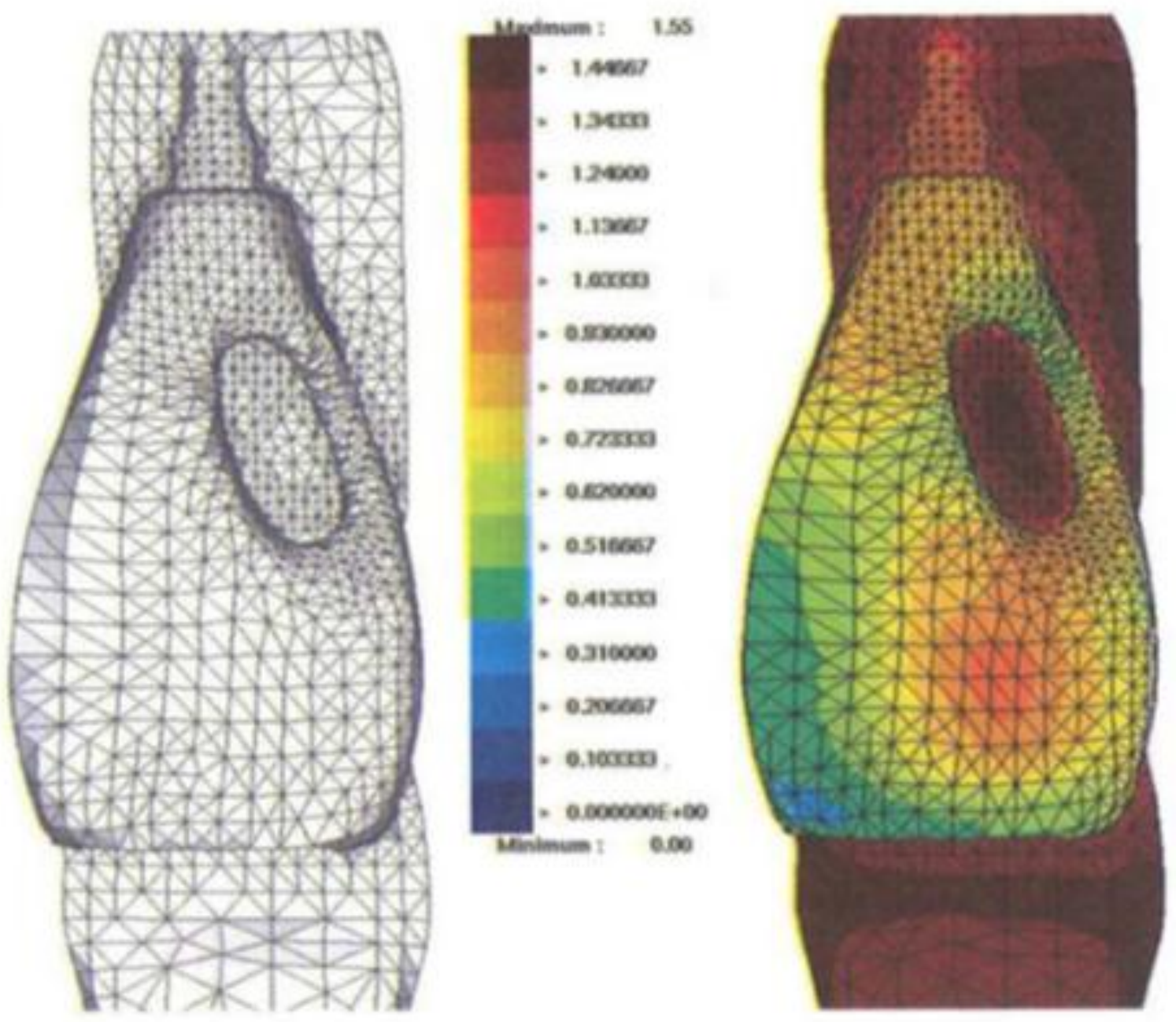

Figure 26: Final mesh (left) and thickness distribution in the bottle (right) (Bellet et al., 2000)

\section{Conclusions}

This paper has described the way industrial polymer processes have developed over the last fifty years and how the associated modelling of polymer processing has become progressively more sophisticated. Currently it is now possible to use commercial software to address many polymer processes and there is an increasing trend to apply a "black box" approach to using this software. This may be appropriate for some situations, however accurately modelling commercial polymer processes remains both challenging and still often requires making "intelligent" simplifying assumptions and approximations.

In the future computing power and advanced numerical techniques will help reduce computation times and add to the precision of numerical solutions, however in the authors view there is still value in making geometric simplifications, realistic rheology assessments and developing a good physical understanding of a process before and during embarking on a "black box" simulation. 
The paper has shown that "isothermal" Laboratory processing flows can now be accurately modelled which helps defining relevant rheological constitutive equations. However extensional flow behaviour also remains an area where accurate simulation is uncertain. Numerical simulations are in general still unable to predict the onset or form of most extrusion instabilities. At present there is no universally accepted constitutive equation that describes all polymer single phase melt behaviour and increasingly more complex polymer compositions are being used with ever more complex constitutive behaviour. In addition rubber polymer compounding and processing continues to defy accurate numerical simulation in spite of its global commercial importance. There therefore remains much to be done both in terms of constitutive equation development and modelling rheologically difficult, but commercially important polymeric materials.

Some important commercial processing flows such as extrusion and injection moulding can be accurately modelled, however where-ever a non isothermal phase transition occurs from solid to melt or melt to solid, the problem becomes more complex. In particular the transition from solid state polymer pellet or powder to a full melt still offers many challenges in relation to accurate modelling as too does the transition from a melt to a final solid product. If the polymer crystallises during solidification there are even greater difficulties and of course flow can also influence both kinetics and the way the polymer crystallises with quite dramatic effects on final product properties (see for example Roozemond and Peters, 2013).

The numerical simulation of polymer processing has now reached the stage where it is used successfully as a genuine design tool for the optimisation of existing processes and in the future it will be able to help develop new processes that will evolve or be invented. The future challenge is to model the macromolecule orientation (amorphous polymer) the structure development (semi-crystalline polymers, size and shape of spherulites, shish-kebab....) and so to predict the mechanical properties of the produced part (elastic modulus but also yield stress, fatigue behavior...).

\section{Acknowledgements}

We would like to acknowledge all the research students and staff who in the past have been part of developing our understanding of polymer melt flow both at MINES ParisTech CEMEF Sophia Antipolis France and The University of Cambridge UK. We would also like to acknowledge both the EU and EPSRC for supporting collaborative projects in the field of polymer processing that has enabled us to work jointly with many different European colleagues both in academia and industry.

\section{References}

Agassant J.F., Avenas P., Carreau P.J., Sergent J.P., Polymer Processing, Principles and Modeling, Hanser, Munich (1991).

Agassant J.F., Baaijens F. , Bastian H., Bernnat A., Bogaerds A.C.B., Coupez T., Debbaut B., Gavrus A.L., Goublomme A., van Gurp M., Koopmans R.J., Laun H.M., Lee K., Nouatin O.H., Mackley M.R., Peters G.W.M. , Rekers G., Verbeeten W.M.H. , Vergnes B., Wagner M.H., Wassner E. and Zoetelief W.F., The matching of experimental polymer processing flows to numerical simulation, Intern. Polym. Proc., 17: 3-10 (2002).

Agassant J.F., Arda D., Combeaud C., Merten A., Münstedt H., Mackley M.R., Robert L., Vergnes B., Polymer processing extrusion instabilities and methods for their elimination or minimisation, Intern. Polym. Proc., 21: 239-255 (2006). 
Agassant J.F. and Haudin J.M., Mise en forme des polymères, in Matériaux Polymères,Ed Marc Carrega, Dunod, (2007).

Agassant J.F., Avenas P., Sergent J.Ph., Vergnes B., Vincent M., Mise en Forme des Polymères, approche thermomécanique de la plasturgie, Tec et Doc, Paris (2014).

Arpin B., Lafleur P.G., Vergnes B., Simulation of a polymer flow through a coat-hanger die: a comparison of two numerical approaches, Polym. Eng. Sci., 32: 206-212 (1992).

Arnold D., Brezzi F., Fortin M., A stable finite element for the Stokes equations, Calcolo, 23: 337-344 (1984).

Arpin B., Lafleur P.G., Sanschagrin B., A personal computer software program for coat-hanger die simulation, Polym. Eng. Sci., 34: 6657-664 (1994).

Bellet M., Monasse B., Agassant J.F., Simulation numérique des procédés de soufflage, Techniques de l’Ingénieur, AM 3705 (2000).

Black.J.R, Denn.M.M, Hsiao.G.C, Creeping flow of a viscoelastic liquid through a contraction, In Theoretical Rheology; Ed J.F.Hutton, J.R.A. Pearson and K.Walters, Applied Science Publishers, 3-30 (1975).

Boitout F., Agassant J.F., Vincent M., Elastic calculation of residual stresses in injection molding, Intern. Polym. Proc., 3: 237-242 (1995).

Boukellal G., Durin A., Valette R., Agassant J.F., Evaluation of a tube-based constitutive equation using conventional and planar elongation flow optical rheometers, Rheol. Acta, 50: 547-557 (2011).

Brinkmann H.C., Heat effects in capillary flow, Appl. Sci. Research, 2: 120-124 (1951).

Brooks A.N., Hughes T.J.R., Streamline upwind / Petrov-Galerkin formulations for convection dominated flows with particular emphasis on the incompressible Navier-Stokes equations, Computer Methods in Applied Mechanics and Engineering, 32: 199-259 (1982)

Cameron A., Principles of lubrication, Longmans Green, London (1966).

Carneiro O.S., Nobrega J.M., Pinho F.T., Oliveira P.J., Computer aided rheological design of extrusion dies for profiles, J. Mat. Proc. Tech., 144: 75-86 (2001).

Castro J.W., Macosko C.W., Studies of mold filling and curing in the reaction injection molding process, AICHE J., 28: 250-260 (1982).

Chiang H.H., Hieber C.A., Wang K.K., A unified simulation of filling and postfilling stages in injection molding; Part I: Formulation, Polym. Eng. Sci., 31: 116-124 (1991).

Cross M.M., Rheology of non-newtonian fluids: a new flow equation for pseudoplastic systems, J.Colloid Sci., 20, 417-437 (1965).

Coupez T., Metric constructionby length distribution tensor and edge based error for anisotropic adaptative meshing, J.Comp.Phys., 230: 2391-2405 (2011).

Dealy J.M. and Wissbrun K.F., Melt rheology and its role in plastics processing, Kluwer Academic Publishers, Dordrecht, (1999).

Demay Y., Instabilités d'étirage et bifurcation de Hopf, Thèse de Doctorat d'Etat, Université de Nice (1983).

De Lorenzi H.G., Nied H.F., Blow molding and thermoforming of plastics : finite element modeling, Comp. Struct., 26: 197-206 (1987).

Denizart O., Vincent M. Agassant J.F., Thermal stresses and strains in injection molding : experiments and computations, J.Mat.Sci., 30: 552-560 ( 1995).

Dreyer J.L., Injection assistée par gaz, Techniques de l’Ingénieur, AM 3693 (2012).

Douven L.F.A., Baaijen F.T.P., Meijer H.E.H., The computation of properties of injection moulded product, Prog. Polym. Sci., 20 : 403-457 (1995).

Dupont S., Extrusion soufflage de grands corps creux, Techniques de l'Ingénieur, AM 3646 (2013).

Farhoudi Y., Kamal M.R., Measurement and computation of thermal stresses in injection molding of HDPE, Int. J. Forming Proc., 2: 277-306 (1999)

Foudrinier E.,Etude numérique et expérimentale du procédé d'extrusion de pâtes argileuses, Thèse de Doctorat, Ecole des Mines de Paris (2007).

Gagon D.K., Denn M.M., Computer-simulation of steady polymer melt spinning, Polym. Eng. Sci., 21: 844-853 (1981).

Gamache E., Soufflage de gaine, Techniques de l’Ingénieur, AM 3702 (2010) 
Gleissle W., Rate or stress controlled rheometry, In Rheological Measurement, Ed A.A.Colyer and D.W.Clegg, Chapman and Hall, 356-391 (1998).

Gobeau J.F., Etude expérimentale et simulation numérique 3D par éléments finis de l'écoulement dans les filières d'extrusion de profilés PVC, Thèse de Doctorat, Ecole des Mines de Paris (1996).

Gonçalves N.D., Carneiro O.S., Nobrega J.M., Design of complex profile extrusion dies through numerical modeling, J. Non-Newtonian Fluid Mech., 100: 103-110 (2013).

Gou Z., McHugh A.J., A comparison of Newtonian and viscoelastic constitutive models for dry spinning of polymer fibers, J. Appl. Polym. Sci., 87: 2136-2145 (2003).

Gruau C., Coupez T., 3D tetrahedral, unstructured and anisotropic mesh generation with adaptation to natural and multidomain metric. Computer Methods in Applied Mechanics and Engineering, 194: 4961-4976 (2005).

Haagh G.A.A.V., Peters G.W.M., Van De Vosse F.N., Meijer H.E.H., A 3D finite element model for gas-assisted injection molding: simulations and experiments, Polym. Eng. Sci., 41: 449-461 (2001).

D'Halewyn S., Etude de l'écoulement d'un mélange d'élastomères dans une filière de profilé, Thèse de Doctorat, Ecole des Mines de Paris (1992).

Hele-Shaw H.S., The motion of perfect fluid, Notes on Proceedings of the Royal Institution of Great Britain, 16: 49-64 (1899).

Hétu J.F., Gao D.M., Garcia-Rejon A., Salloum G., 3D finite element method for the simulation of the filling stage in injection molding, Polym. Eng. Sci., 38: 223-236 (1998).

Hieber C.A., Shen S.F., A finite-element/finite-difference simulation of the injection-molding filling process, J. Non-Newt. Fluid Mech., 7: 1-32 (1980).

Huilier D., Terrisse J., de la Lande M.E., Latrobe A., Modeling the packing-cooling stage in injection molding of amorphous polymers, Intern. Polym. Proc., 4: 184-190 (1988)

Huneault M.A., Lafleur P.G., Carreau P.J., Evaluation of the PAN technique for profile die design, Intern. Polym. Proc., 11: 50-57 (1996).

Hurez P., Tanguy P.A., Blouin D., Numerical simulation of profile extrusion dies without flow separation, Polym. Eng. Sci., 33: 971-979 (1993).

Jarecki L., Ziabicki A., Viscosity effects in computer modeling of fiber spinning from crystallizing polymer melts, Polimery, 49: 101-109 (2004).

Kabanemi K.K., Simulation numérique par elements finis du retrait et du compactage en moulage par injection, Thèse de Doctorat, Université Catholique de Louvain, Belgique (1991).

Kabanemi K.K., Vaillancourt H., Wang H., Salloum G., Residual stresses, shrinkage, and warpage of complex injection molding products : numerical simulation and experimental validation, Polym. Eng. Sci., 38: 21-37 (1998).

Kalika D.S., Denn M.M., Wall slip and extrudate distorsion in linear low density polyethylene, J.Rheol., 31: 815-834 (1987).

Kamal M.R., Kenig S., The injection molding of thermoplastics. Part I: Theoretical model, Polym. Eng. Sci., 12: 294-301 (1972).

Kamal M., Kuo Y., Doan P.H., The injection molding behavior of thermoplastics in thin rectangular cavities, Polym. Eng. Sci., 15: 863-868 (1975).

Kamal M.R., Lai-Fook R.A., Hernandez-aguilar J.R., Residual thermal stresses in injection moldings of thermoplastics: a theoretical and experimental study. Polym. Eng. Sci., 42: 1098-1114 (2002).

Keunings R.,Simulation of viscoelastic fluid flow, in: Fundamentals of Computer Modeling for Polymer Processing, Ed C.L. Tucker III., Hanser, Munich, 402-470 (1989).

Kim S.W., Turng L.S., developments of three-dimensional computer-aided engineering simulation for injection molding, Modell. Simul. Mat. Sci. Eng., 12: 151-173 (2004)

Lafleur P.G., Vergnes B., Polymer extrusion, Wiley (2014).

Langkamp U., Michaeli W., On-line monitoring of parison geometry to prevent sag and swell, Plast. Eng., 52: 29-31 (1996).

Lee.K, and Mackley.M.R . The importance of slip in matching polyethylene processing data with numerical simulation. J Non Newtonian Fluid Mech 94 159-177 (2000).

Lee K.and Mackley M.R., The application of the Multi-Pass rheometer for precise rheo-optic characterisation of polyethylene melts, Chemical Engineering Science, 56: 5653-5661 (2001). 
Likhtman A. E., and R. S. Graham, Simple constitutive equation for linear polymer melts derived from molecular theory: Rolie-Poly equation,” J. Non-Newtonian Fluid Mech. 114: 1-12 (2003).

Lodge A.S., Elastic liquids, Academic Press, New-York (1964).

Mackley M.R., Marshall R.T.J., Smeulders J.B.A.F. and Zhao F.D., The rheological characterization of polymeric and colloidal fluids. Chem Eng Sci. 49,16, 2551-2565 (1994).

Mackley M.R., and Hassell D.G., The Multipass Rheometer; a review, J. of Non-Newtonian Fluid Mech., 166: 421-456 (2011)

Maillefer C., Boudineuses à vis, Swiss Patent nº 363149 (1959).

Marrucci G., Ianniruberto G., Flow induced orientation and stretching of entangled polymers, Philosophical Transaction of the Royal Society of London, Series A- Mathematical Physical and Engineering Series, 361: 677-687 (2003).

Mavridis H., Hrymak A.N., Vlachopoulos J, Finite element simulation of fountain flow in injection molding, Polym. Eng. Sci., 26, 449-454 (1986).

McKelvey J.M., Polymer processing, Wiley, New-York (1962)

McKinley G.H., Pakdel P., Oztekin A.,Rheological and geometric scaling of purely elastic flow instabilities, J. Non-Newtonian Fluid Mech., 67, 19-47 (1996).

McLeisch T.C.B., Larson, R.G., Molecular constitutive equation for a class of branched polymers: The Pom-Pom polymer, J.Rheol., 42: 81-110 (1998).

Mooney M., Explicit formula for slip and fluidity, Trans. Soc. Rheol., 2, 210-222 (1931).

Papanastasiou A.C., Scriven L.E., Macosko C.W., An integral constitutive equation for mixed flows: viscoelastic characterization, J.Rheol., 27: 387-410 (1987).

Papanastasiou A.C., Macosko C.W., Scriven L.E., Chen Z., Fiber spinning of viscoelastic liquids, AICHE J., 33: 834-842 (1987).

Pearson J.R.A., Mechanical Principles of Polymer Melt Processing, Pergamon Press, Oxford (1966).

Phan Thien N., Tanner R.I., A new constitutive equation derived from network theory, J. Non-Newt. Fluid Mech., 2: 353-365 (1977).

Pichelin E., Coupez T., Finite element solution of the 3D mold filling problem for viscous incompressible fluid, Comput. Meth. Appl. Mech. Eng., 163 : 359-371 (1998).

Plantamura B., Soufflage de corps creux biorientés, Techniques de l'Ingénieur, AM 3700 (2012)

Potente H., Schöppner, A throughput model for grooved bush extruders, Intern.Polym.Proc.,10: 289295 (1995)

Rauwendaal C., Polymer Extrusion, $4^{\text {th }}$ edition, Hanser, Munich (2001)

Rodriguez-Villa A., Agassant J.F., Bellet M., Finite element simulation of the extrusion blow-molding process, in : Simulation of material processing, theory, methods and applications, Ed Shen S.D. and Dawson P., Balkerma, Amsterdam, 1053-1058 (1995)

Roozemond, P.C., Peters, G.W.M., Flow-enhanced nucleation of poly (1-butene) : model application to short-term and continuous shear and extensional flow, J. Rheology, 57:1633-1652 (2013)

Ruymbeke E.V., Keunings R., Bailly C., Determination of the molecular weight distribution of entangled linear polymers from linear viscoelasticity data, J. Non-Newtonian Fluid Mech., 105 $153-175$ (2002).

Saillard P., Agassant J.F.,Polymer flow in a spiral mandrel die for tubular films, Polym. Proc. Eng., 2: 37-52 (1984).

Silva L., Gruau C., Agassant J.F., Coupez T., Mauffrey J., advanced finite element 3D injection molding, Intern.Polym. Proc., 20: 265-273 (2005).

Silva L., Agassant J.F., Coupez T., Three dimensional injection molding simulation, In: Injection molding. Technology and fundamentals, Kamal M.R., Isayev A., Liu S.J. editors, Hanser, Munich, 599-651 (2009).

Silva L., Valette R., Laure P., Coupez T., A new three-dimensional mixed finite element for direct numerical simulation of compressible viscoelastic flows with moving free surfaces, International journal of material forming, 5: 55-72 (2012).

Tadmor Z., Klein I., Engineering Principles of Plasticating Extrusion, Van Nostrand Reinhold, New York (1970).

Tadmor Z., Gogos C.G., Principles of Polymer Processing, $2^{\text {nd }}$ edition, Wiley, New-York (2006).

Titomanlio G., Brucato V., Kamal M.R., Mechanism of cooling stress build-up in injection molding of thermoplastic polymers, Intern. Polym. Proc., 2: 55-59 (1987). 
Titomanlio G., Piccarolo S., Levati G., On the packing-holding flow in the injection molding of thermoplastic polymers, J. Appl. Polym. Sci., 35:1483-1495 (1988).

Trouton F.T., On the coefficient of viscous traction and its relation to that of viscosity, Proc Roy Soc London, A77: 426-440 (1906).

Valette R., Laure P., Demay Y., Agassant J.F., Experimental investigation of the development of interfacial instabilities in two-layer coextrusion flow, Intern. Polym. Proc., 19: 118-128 (2004).

Valette R., Mackley M.R., and Hernandez Fernandez del Castillo G., Matching time dependent pressure driven flows with a Rolie Poly numerical simulation, J. of Non-Newtonian Fluid Mech., 136: 118-125 (2006).

Vergnes B., Saillard P., Plantamura B., "Berechnungsmethoden für Breitschlitz Extrusionwerkzeuge", Kunststoffe, 70: 750-752 (1980).

Vergnes B;, Saillard P., Agassant J.F., Non-isothermal flow of a molten polymer in a coat-henger die, Polym. Eng. Sci., 24: 980-987 (1984).

Vergnes B., Bennani N.,Guichard C., Experimental and theoretical approach tot he extrusion of rubber compounds with a two-stage extruder, Intern.Polym.Proc., 1: 19-24 (1986)

Vergnes B., Agassant J.F., Modélisation des écoulements dans les filières d'extrusion, Techniques de l’Ingénieur, AM 3 655, (2008).

Wagner M.H., Analysis of time-dependent non-linear stress-growth data for shear and elongational flow of a low-density branched polyethylene melt, Rheol.Acta 15: 136-142 (1976).

Wang V.W., Hieber C.A., Wang K.K., Dynamic simulation and graphics for the injection molding of three-dimensional thin parts, J. Polym. Eng., 7: 21-45 (1986).

White J.L., Metzner A.B., "Development of constitutive equations for polymeric melts and solutions", J. Appl. Polym. Sci., 7:1867-1889 (1963).

William M.L. Landel R.F., Ferry J.D., Temperature dependence of relaxation mechanisms in amorphous polymers and other glass forming liquids, J.Am. Chem. Soc., 77: 3701-3706 (1955).

Willien J.L., Modélisation surfacique du remplissage de moules en injection des thermoplastiques. Thèse de Doctorat, Ecole des Mines de Paris (1992).

Wilson J.M., Khomami B., An experimental investigation of interfacial instabilities in multilayer flow of viscoelastic fluids. II. Elastic and nonlinear effects in incompatible polymer system, J.Rheol., 37: 315-339 (1993).

Yasuda K.Y., Amstrong R.C., Cohen R.E., Shear flow properties of concentrated solutions of linear and star branched polystyrenes, Rheol Acta, 20: 163-178 (1981). 